\title{
Pancreas-specific miR-216a regulates proliferation and endocrine and exocrine cell function in vivo
}

Suheda Erener ${ }^{1,2}$, Cara E. Ellis ${ }^{1}$, Adam Ramzy ${ }^{1}$, Maria M. Glavas ${ }^{1}$, Shannon O` Dwyer ${ }^{1}$, Sandra Pereira ${ }^{1}$, Tom Wang ${ }^{1}$, Janice Pang ${ }^{1}$, Jennifer E. Bruin ${ }^{1,3}$, Michael J. Riedel ${ }^{1}$, Robert K. Baker $^{1}$, Travis D. Webber ${ }^{1}$, Janel L. Kopp ${ }^{1}$, Stephan Herzig ${ }^{2}$, Timothy J. Kieffer ${ }^{1,4}$

${ }^{1}$ Department of Cellular \& Physiological Sciences, Life Sciences Institute, University of British Columbia, Vancouver, BC, Canada

${ }^{2}$ Institute for Diabetes and Cancer, Helmholtz Center Munich, Neuherberg, Germany; Joint Heidelberg-IDC Translational Diabetes Program, Inner Medicine 1, Heidelberg University Hospital, Heidelberg, Germany; Technical University Munich, 85764 Neuherberg, Germany; Deutsches Zentrum für Diabetesforschung, 85764 Neuherberg, Germany

${ }^{3}$ Department of Biology and Institute of Biochemistry, Carleton University, Ottawa, Ontario, Canada

${ }^{4}$ Department of Surgery, University of British Columbia, Vancouver, BC, Canada

Short title: miR-216a regulates endocrine and exocrine cell function

Key words: miR-216a, $\beta$-cell mass, diabetes, PDAC

Abstract word count: 246

Total word count: 7446 (including methods)

Disclosure Statement: The authors have nothing to disclose. 


\section{Abstract}

Pancreas is a vital organ composed of exocrine and endocrine cells that aid digestion of food and regulate blood glucose levels. Perturbations in the function of pancreatic cells leads to the development of life-burdening and/or threatening diseases such as diabetes and pancreatic cancer. Thus, it is critical to understand the molecular check-points that maintain normal pancreas physiology. MicroRNAs (miRNAs) are small non-coding RNAs involved in regulating gene expression in normal and diseased tissues. Several miRNAs have tissuespecific patterns consistent with crucial functions in many biological processes. Yet, there is limited knowledge about the role of pancreas-specific miRNAs in pancreatic pathologies. Here, we report that miR-216a is a conserved, pancreas-specific miRNA that is expressed in both endocrine and exocrine cells. Deletion of miR-216a in mice leads to reduced $\beta$-cell mass and a reduction in islet size under both chow and high-fat diet feeding conditions. We show that inhibition of miR-216a increases apoptosis and decreases cell proliferation in $\beta$ - and exocrine cells. Smad7 is upregulated in miR-216a deficient islets and cell cycle and proliferation are among the most significantly regulated biological processes in miR-216 knockout pancreata. Re-introduction of miR-216a in the pancreatic cancer line, PANC-1, increases cell migration more than 2-fold. In vivo, deletion of miR-216a in the pancreatic cancer prone mouse line $\operatorname{Kras}^{G 12 D}$;Ptfla ${ }^{C r e E R}$ inhibits the propensity of pancreatic cancer precursor lesions. Our study identifies miR-216a as an important pancreas-specific miRNA which may have implications for both diabetes and pancreatic cancer. 


\section{Introduction}

The pancreas, an abdominal organ located behind the stomach, is composed of two major functional compartments. The exocrine pancreas, mainly comprised of acinar cells, aids digestion by secreting digestive enzymes amylase and lipase via pancreatic ducts into the duodenum while the endocrine pancreas, consisting of the islets of Langerhans, maintains normal glucose homeostasis. Islets are interspersed within the exocrine pancreas and consist of five different endocrine cells required for energy metabolism. The $\beta$-cells comprise 50$80 \%$ of the islets ${ }^{1}$ and are responsible for secreting insulin in response to changes in glucose levels. Perturbations in the function of endocrine and exocrine cells leads to the development of life-burdening and/or threatening diseases such as diabetes and pancreatic cancer. While diabetes is characterized by hyperglycemia resulting from defects in insulin secretion, insulin action, or both ${ }^{2}$, pancreatic ductal adenocarcinoma, a major form of pancreatic cancer in humans, results from the abnormal proliferation of the exocrine cells in response to oncogenic mutations $^{3}$. To date many protein coding genes necessary for pancreas development and function have been identified, but the role of the majority of small RNAs is still unclear.

Micro-RNAs (miRNAs) are short ( 21-22 nt long) non-coding RNAs, which have emerged in the last two decades as buffers of signalling pathways to maintain normal tissue development and function ${ }^{4}$. Mature miRNAs function as evolutionarily conserved post-transcriptional gene regulators that mainly decrease the stability or inhibit translation of messenger RNAs (mRNAs) through binding to complementary sequences ${ }^{5}$. A single miRNA can impact the regulation of hundreds of genes with multiple targets ${ }^{6}$ within cellular networks that enable modulation of entire pathways in the context of an individual biological process ${ }^{7}$. Many miRNAs are conserved in sequence between distantly related organisms, suggesting that these molecules participate in essential processes. Recently, a study identified 3,707 novel mature miRNAs by analyzing 1,323 short RNA sequencing samples from 13 different human tissue 
types $^{8}$, providing evidence that the repertoire of human miRNAs is far more extensive than that of public repositories and of what was previously anticipated ${ }^{9}$. Interestingly, many of the newly discovered miRNAs possess tissue specific patterns, akin to proteins. The functional impact of these miRNAs on various diseases remains to be investigated.

In the pancreas, conditional deletion of the miRNA processing endonuclease Dicer at the onset of pancreatic development (e9.5) using a Pdx1-Cre strain results in defects in all pancreatic lineages with dramatic reduction in the ventral pancreas as well as a reduction in the overall epithelial contribution to the dorsal pancreas at e $18.5^{10}$. Postnatal Dicer ablation in the $\beta$-cells using the conditional RIP2-Cre $e^{11,12}$ or $P d x 1-C r e E R^{13}$ strain impairs islet architecture, insulin secretion, and $\beta$-cell mass while deletion of Dicer in the acinar cells using the Mist1-CreERT mice ${ }^{14}$ promotes epithelial to mesenchymal transition accompanied by acinar to ductal metaplasia. Although previous findings demonstrate important roles for Dicer in the pancreas, in vivo studies investigating the role of individual miRNAs in pancreas development and endocrine and exocrine function are limited. Furthermore, the majority of investigated miRNAs do not have pancreas-specific expression.

Tissue-specific patterns of gene expression play fundamental roles in tissue development and function $^{15}$. Although the majority of miRNAs are ubiquituosly expressed, some miRNAs exhibit tissue-specific ${ }^{8}$ or developmental-stage-specific expression patterns and contribute to maintaining normal tissue identity and function ${ }^{16}$. Furthermore, tissue-specific miRNAs are associated with various human diseases such as cardiovascular disease ${ }^{17}$ and cancer ${ }^{18}$. Therefore, it is critical to unravel the tissue specific regulatory networks to better understand the molecular mechanisms underlying diseases and identify new disease genes. In this study, we hypothesized that pancreas-enriched miRNAs have specific, critical roles for pancreas development and/or function and hence sought to identify miRNAs enriched in the pancreatic 
118 cells. Our results show that miR-216a is a pancreas-specific miRNA with critical functional

119 roles in both endocrine and exocrine cells.

120 


\section{Results}

122 To identify the miRNAs that are enriched in pancreatic islets, we performed miRNA profiling

123 from adult human islets and compared it to embryonic stem (ES) cells. We identified nine

124 miRNAs that showed greater than 3-fold expression in human islets compared to ES cells

125 (Figure 1a). Out of the nine miRNAs identified, only miR-216a showed a pancreas- specific

126 expression pattern (Figure 1b) while the eight other miRNAs were ubiquitously expressed in

127 the analyzed tissues (Suppl. Figure 1a). To examine whether miR-216a levels are changed

128 during endocrine cell development, we differentiated human ES cells to pancreatic like cells.,

129 When comparing sequential timepoints, the single largest increase in levels of miR-216a

130 occurred on day 14 (Figure 1c) of the differentiation protocol, which marks the generation of

$131 \mathrm{PDX} 1^{+} / \mathrm{NKX} 6.1^{+}$pancreatic endocrine progenitor cells ${ }^{19}$. miR-216a levels further increased

132 during differentiation, reaching the highest levels at the final stage of differentiation (days 26-

133 33), correlating with the presence of pancreatic endocrine cells. To further investigate miR-

134 216a expression during development, we performed in situ hybridization with human fetal

135 pancreatic tissue using DIG labelled miR-216a-LNA probes. There was a faint staining in the

136 pancreatic tissue at the gestational time 8 weeks 4 days ( $8 \mathrm{~W} 4 \mathrm{~d}$ ) (Figure 1d), during the time

137 when insulin and glucagon double positive cells emerge ${ }^{20}$. However, we detected strong miR-

138 216a staining in the branching pancreatic epithelium that harbor PDX1+ / NKX6.1+

139 pancreatic endocrine progenitor cells ${ }^{20}$. Analysis of human adult pancreas also revealed strong

140 pancreatic miR-216a staining with further enrichment in pancreatic islets (Figure 1d). To

141 further investigate the specificity of miR-216a for pancreatic tissue, we performed in situ

142 hybridization on kidney capsule grafts obtained from mice and rats implanted with pancreatic

143 progenitor cells that had developed to endocrine cells ${ }^{21}$. There was strong reactivity for miR-

$144216 \mathrm{a}$ in the grafts whereas neighboring kidney sections had no detectable staining (Suppl.

145 Figure 1b). We next examined the miR-216a sequence across diverse species and found it to

146 be highly conserved (Figure 1e), suggestive of a functional importance. A thorough tissue 
147 expression analysis from C57BL/6 mice showed miR-216a levels were specifically expressed

148 in the pancreas with further enrichment in pancreatic islets (Figure 1f), akin to our results

149 with human tissues, suggesting a role for miR-216a miRNA in islet development and/or

150 function.

152 To explore the role of miR-216a in pancreatic islet function in vivo, we generated miR-216a

153 knock-out mice (miR-216a KO) in which the precursor sequence of miR-216a (pre-miR-216)

154 was deleted by homologous recombination ${ }^{22}$. qRT-PCR analysis for miR-216a using total

155 RNA from isolated islets of miR-216a KO mice revealed that miR-216a was not detected

156 (Suppl. Fig 2a). KO mice were viable and there were no significant differences in fasting

157 body weight, blood glucose and insulin levels from newly weaned 3-4 weeks old miR-216a

158 KO and littermate wild-type (WT) mice (Suppl. Fig 2b-d). Pancreas weight and pancreatic

159 cell size were unchanged (Suppl. Fig 2e-f). We next monitored the miR-216a KO mice

160 weekly for over 20 weeks for changes in body weight and blood glucose levels. miR-216a KO

161 mice were comparable to WT littermate controls (Figure 2a, b). Oral glucose tolerance tests

162 performed at 10 and 15 weeks of age revealed no significant genotype differences in blood

163 glucose (Figure 2c, Suppl. Figure 2e) or insulin levels (Figure 2d). Similarly, miR-216a KO

164 mice had normal insulin tolerance at 12 weeks of age and response to arginine injection at 18

165 weeks (Figure 2e, Suppl. Figure 2f). We next assessed whether islets from miR-216a KO

166 mice had altered insulin secretion ex vivo. Glucose $(16.7 \mathrm{mM})$ stimulated insulin secretion

167 from miR-216a KO islets was comparable to WT islets albeit insulin release was significantly

168 lower at $2.8 \mathrm{mM}$ glucose (Figure 2f). Correspondingly, islets isolated from the miR-216a KO

169 mice appeared generally smaller than the WT islets (Figure $\mathbf{2 g}, \mathbf{h}$ ), and lacked the bigger

170 islets with a trend towards an increased number of smaller islets (Figure 2i). To analyze the

171 effect of miR-216a KO on islet structure in more detail, we performed immunostaining with

172 fixed pancreas tissue harvested from 21-week old adult mice. Immunostaining with insulin 
and glucagon antibodies demonstrated that $\beta$-cell mass was significantly reduced in the miR216a KO mice while $\alpha$-cell mass was unchanged (Figure 3a-c). Islet circularity and the location of $\alpha$-cells were unchanged (Suppl. Fig 3a). Consistent with the isolated islet data, the area of islets determined by synaptophysin immunostaining was significantly smaller in miR-216a KO mice (Figure 3a, d) and miR-216a KO pancreatic sections harbored less of the larger islets (Figure 3e). To examine whether the effects of miR-216a on $\beta$-cell mass and islet size was postnatally regulated, we performed the same analysis in newborn mice. Average islet size in one-day old miR-216a KO pups was comparable to WT littermates (Figure 3f, g), with no statistical difference in various islet size groups (Figure 3f, h). Interestingly, there was a trend towards an increased frequency for larger islets in the miR-216a KO pups (Figure 3h). $\beta$-cell and $\alpha$-cell area were not different as well as islet circularity and peripheral $\alpha$-cells in one day old pups (Suppl. Figure 3b-c).

To explore the reasons for smaller islet size and reduced $\beta$-cell mass in miR-216a KO mice, we first examined the key hormones and transcription factors regulating endocrine cell identity. Expression of Insulin, Glucagon, $P d x 1$, and $N k x 6.1$ were not changed in islets from miR-216a KO mice (Suppl. Fig 4a). We next investigated whether miR-216a alters cell migration and proliferation. Regulation of islet size is complex and involves cellular processes such as fusion, fission, growth and migration ${ }^{23}$. Cell migration is critical for both islet formation and the movement of islets away from ducts ${ }^{24,25}$. We transfected pancreatic ductal adenocarcinoma PANC-1 cells that have very low miR-216a levels (not shown) and migration ability with control (ctrl) or miR-216 mimetics and performed a migration assay using transwell chambers. Quantification of the cells that traversed the boyden chambers demonstrated that miR-216a more than doubled the number of migrating cells compared to untransfected and control miRNA transfected wells (Figure 4a). We next assessed the migration ability of miR-216a KO islet cells ex vivo. We coated cell culture plates with the 
matrix secreted by $804 \mathrm{G}$ cells and monitored the spreading of islets by light microscopy. Five days post-seeding, more WT islets spread compared to miR-216a KO islets while miR-216a KO islets had more defined borders (Figure 4b).

TGF- $\beta$ signalling regulates pancreatic epithelium branching and cell migration to form islet clusters $^{26}$. It has been previously shown that miR-216a expression is regulated by TGF- $\beta$ signalling and alters expression of $\operatorname{Pten}^{27,28}$ and $\operatorname{Smad} 7^{28}$. To investigate the potential signalling pathways regulating miR-216a expression in the pancreas, we treated EndoC- $\beta \mathrm{H} 1$ cells, which have high endogenous miR-216a levels, with a TGF- $\beta$ agonist TGF- $\beta 1$ and the inhibitor SB431542 and measured miR-216a levels by qPCR. TGF- $\beta 1$ treatment significantly increased miR-216 expression and inhibition of TGF signalling with SB431542 significantly decreased miR-216a levels (Figure 4c-d). We next examined mRNA levels of potential miR216a target genes in the pancreatic islets of WT and miR-216a KO mice. qRT-PCR analysis from islets of WT and miR-216a KO mice indicated that Smad7 expression was significantly 211 upregulated in the miR-216a KO islets whereas Pten levels were not changed (Figure 4e).

212 TGF- $\beta$ signalling and Smad7 are known regulators of cell migration and their mode of action 213 is thought to be via altering the expression of genes involved in regulating extracellular matrix 214 composition $^{29}$. We analyzed the levels of ECM genes in miR-216a transfected cells using an 215 extracellular matrix (ECM) gene array. miR-216a altered the expression of 12 genes out of 216 the 87 genes analyzed (Figure 4f). Levels of genes involved in basement membrane such as 217 Col4a2, Ecm 1, Fbln1, Lama3, Lamb2, Lamb3 were upregulated in the miR-216a transfected 218 cells suggesting that TGF- $\beta$ induced miR-216a can increase cell migration by altering the 219 extracellular matrix integrity of basement membrane. We next investigated whether inhibition 220 of miR-216a can affect cell proliferation and cell death by transfecting INS-1E $\beta$-cells with 221 miR-216a and a control scrambled miRNA inhibitor. INS-1E $\beta$-cells have higher levels of 222 miR-216a as compared to other rodent $\beta$-cell lines such as MIN6 (not shown) thus were 
chosen for miR-216a inhibition experiments. Inhibition of miR-216a significantly reduced cell proliferation compared to control miRNA inhibitors (Figure 4g). Analysis of cell death using live cell imaging indicated that inhibition of miR-216a in the presence of cytotoxic factors (TNF- $\alpha$, IFN- $\gamma$, IL-1 $)$ increased the rate of apoptosis (Figure 4h) providing a possible mechanism for the smaller islet size.

Many miRNAs display their functional role under metabolic stress or upon cell insult ${ }^{30}$. We first explored whether miR-216a levels were altered in the islets of leptin knock-out (LepKO) rats, a model for metabolic overload with disturbed glucose and energy metabolism and larger islets $^{31}$. Indeed miR-216a levels were significantly higher in the LepKO rat islets whereas levels of another well-studied islet enriched miRNA, miR-375, were unchanged (Figure 5a). Although glucose metabolism in miR-216a KO mice was comparable to WT mice under chow-diet conditions, we next assessed whether reduced islet size and $\beta$-cell mass in miR216a KO mice could result in impaired glucose homeostasis under high-fat diet conditions. miR-216a KO mice and the littermate WT controls were placed on $60 \%$ high-fat diet for eight weeks. Fasting body weight and blood glucose levels were comparable throughout the study (Figure 5b-c). An oral glucose tolerance test performed 2 weeks after HFD feeding also revealed no significant differences in blood glucose levels (Figure 5d), but miR-216a KO mice secreted less insulin in response to glucose administration (Figure 5e). Similarly, repetition of the oral glucose tolerance test 6 weeks after HFD feeding showed no differences in blood glucose levels (Figure 5f). However, miR-216a KO mice showed a trend towards reduced insulin secretion with significance at the basal time-point prior to oral glucose delivery (Figure 5g). Insulin tolerance tests performed three and eight weeks after HFD feeding indicated similar insulin sensitivity of miR-216a KO and WT mice (Figure 5h-i). Consistent with the reduced insulin secretion observed in the miR-216a KO mice, the animals had significantly reduced $\beta$-cell mass compared to controls (Figure $\mathbf{5 j} \mathbf{j} \mathbf{l}$ ). In agreement with 
reduced $\beta$-cell mass, miR-216a KO mice had decreased circulating miR-375 levels (Figure

$249 \mathbf{5 m}$ ), a miRNA that is highly expressed in the $\beta$-cells ${ }^{32}$ and is detected in the circulation ${ }^{33,34}$.

250 We next measured plasma insulin and proinsulin levels to investigate whether the decreased

$251 \beta$-cell mass was reflected in circulating insulin levels and whether $\beta$-cell work load was

252 comparable between WT and miR-216a KO mice. Plasma insulin levels were comparable

253 between WT and KO mice however, proinsulin levels were significantly decreased in the

254 miR-216a KO mice (Figure 5 n-o), suggesting increased insulin processing in the KO $\beta$-cells

255 to meet the metabolic demands. The degree of cell proliferation was comparable in the WT

256 and miR-216a KO $\beta$-cells as assessed by PCNA immunostaining (Figure $\mathbf{5}$ j,p). To examine

257 islet size, pancreata were immunostained for synaptophysin (Figure $5 \mathbf{~ k}$ ). Like mice on chow

258 diet, miR-216a KO mice fed HFD also had significantly smaller islets (Figure 5q), with

259 increased frequency of smaller islets and decreased occurrence of larger islets (Figure 5r).

260 Overall, these data indicate that under metabolically stressed condition of HFD, miR-216a

261 KO mice secrete lower insulin during a glucose challenge and have decreased islet size with

262 reduced $\beta$-cell mass and increased markers of $\beta$-cell stress.

264 Although we determined that Smad7 expression was increased in the islets of miR-216a KO

265 mice, we sought to perform a global analysis to further explore signalling pathways targeted

266 by miR-216a in the whole pancreas. We performed RNA-sequencing from the pancreata of

267 one day old WT and miR-216a KO mice. The RNA integrity number (RIN) obtained from the

268 pancreata of miR-216a KO mice were all above 8 and suitable for RNA-sequencing (not

269 shown). We examined the top 50 most abundant genes expressed in WT and miR-216a KO

270 pancreata and observed the expected abundance for Amylase, Trypsin and Insulin, yet they

271 were not significantly different between WT and miR-216a KO mice (Figure 6a).

272 Differential gene expression analysis from all the transcripts using an adjusted p-value $<0.05$

273 revealed 409 genes were differentially expressed between WT and KO pancreata (Suppl. 
table 1). To identify more globally the affected biological processes in the miR-216a KO

275 pancreata, we next performed a Gene Ontology analysis and found cell cycle to be most

276 significantly altered (Figure 6b). Similarly, KEGG pathway analysis indicated cell cycle,

277 DNA replication and repair pathways were statistically different in the miR-216a KO versus

278 WT pancreata (Figure 6c). Next, we compared the expression of genes involved in cell cycle

279 pathways between WT and miR-216a KO pancreata and observed that many cyclin dependent

280 kinases (e.g: $C d k 4, C d k 1)$ and cyclins (e.g: $C c n e l)$ as well as DNA replication genes (e.g:

281 Pcna, Mcm2, Mcm5) were decreased in the pancreas of miR-216a KO mice (Figure 6d). This

282 was consistent with our observation that inhibition of miR-216a decreases cell proliferation in

283 INS-1E $\beta$-cells (Figure 4g) and the presence of reduced $\beta$-cell mass and islet size in the miR-

284 216a KO mice. A map of the cell cycle pathway with genes significantly regulated in miR-

285 216a KO pancreata is shown in (Suppl. Fig 5). To investigate the effect of miR-216a on cell

286 proliferation in cells with exocrine origin, we transfected human PANC-1 cells with the miR-

287 216a mimetic and another miRNA, miR-217. Similar to INS1-1E $\beta$-cells, miR-216a

288 transfection significantly increased the number of cells (Figure 6e), and decreased the rate of

289 apoptosis (Figure 6f), thus confirming the role of miR-216a in regulating cell proliferation in

290 another pancreatic cell type.

292 We next investigated whether the absence of miR-216a alters the progression of a pancreatic 293 pathology related to cell cycle/proliferation in acinar cells. Oncogenic KRAS can induce

294 pancreatic ductal adenocarcinoma (PDAC) precursor lesions from pancreatic acinar cells ${ }^{35,36}$.

295 A number of studies have shown that PDAC develops from abnormally proliferating cells in 296 the precursor lesions termed pancreatic intraepithelial neoplasia (PanIN) $)^{37}$, the most common 297 precursor lesions observed in humans. A mutation in KRAS oncogene is currently considered 298 as the initiating factor in pancreatic cancer $^{38}$. Expression of constitutively active Kras $^{G 12 D}$ 299 allele in mice induces PanINs and after a significant latency period PDAC ${ }^{39}$. We crossed 
$300 \quad$ miR-216a KO mice with the pancreatic cancer prone $\operatorname{Kras}^{G 12 D}$;Ptfla ${ }^{C r E E R}$ mice (Figure 7a)

301 and analyzed the frequency of PanINs in the pancreata of offspring. As expected, H\&E

302 staining from the pancreata of $\operatorname{Kras}^{G 12 D} ; P_{t f 1 a^{C r e E R} ; m i R-216 a^{(++)}}$mice revealed widespread

303 lesions with columnar to cuboidal cells with varying degrees of cytological and architectural

304 atypia (Figure 7b). In contrast, the pancreata of mice lacking miR-216a had limited

305 neoplastic lesions. Further histological analysis with Alcian blue staining confirmed the

306 histological characteristic of high acidic mucin content of PanINs in the WT mice, whereas

307 miR-216a KO pancreata had decreased PanIN frequency (Figure 7c). In

$308 \mathrm{Kras}^{G 12 D} ; \mathrm{Ptfla} \mathrm{CreER}^{\mathrm{B}} ; \mathrm{miR}-216 \mathrm{a}^{(--)}$mice there was more than 2-fold reduction in the Alcian

309 blue $^{+}$area compared to $\mathrm{Kras}^{G 12 D} ; P t f 1 a^{C r e E R} ; m i R-216 a^{(+/+)}$mice. (Figure 7d). These data

310 indicate that acinar cells from the miR-216a ${ }^{(-/-)}$mice have less propensity than miR-216a $\mathrm{a}^{(+/+)}$

311 mice to form PanINs and acinar to ductal metaplasia in response to oncogenic KRAS. 


\section{Discussion}

314 We predicted that pancreas-enriched miRNAs likely have specific, critical roles for pancreas

315 development and/or function and hence sought to identify miRNAs enriched in pancreatic

316 cells. Our results show that miR-216 is a highly conserved pancreas-specific miRNA with

317 roles in both endocrine and exocrine cell function. In the endocrine pancreas, we found that

318 miR-216a regulates $\beta$-cell mass and islet size by increasing cell proliferation and migration. In

319 the exocrine pancreas, miR-216a regulated cell cycle and proliferation and deletion of miR-

320 216a decreased the formation of PanINs, implicating miR-216a in the progression of

321 pancreatic pathologies such as diabetes and cancer.

322 miR-375 was the first reported islet "specific" miRNA ${ }^{32}$ with a role in maintaining normal $\alpha$ -

323 and $\beta$-cell mass ${ }^{45}$. To our knowledge our study is the first to identify a pancreas-specific

324 miRNA with functional roles in both endocrine and exocrine pancreas. Although we also

325 observed an enrichment for miR-375 in human and mouse islets, it is also expressed at high

326 levels in other tissues and non-pancreatic roles for this miRNA have been identified, such as

327 in the regulation of gut mucosal immunity ${ }^{46}$ and gastric tumorigenesis ${ }^{47}$. Specificity of miR-

328 216a for the pancreas suggests clinical opportunities to exploit this miRNA as a biomarker in

329 pancreatic pathologies. Indeed, Goodwin et al. have shown that circulating miR-216 levels are

330 increased in a mouse model of acute pancreatitis ${ }^{48}$. Szafranska et al. have shown that

331 pancreatic tissue from PDAC patients have a large decrease in miR-216 expression ${ }^{49}$ and

332 others have shown that miR-216 levels are lower in fecal specimens of patients with chronic

333 pancreatitis and pancreatic cancer ${ }^{50}$. Further studies are required to evaluate the utility of

334 miR-216a as serum biomarker of pancreatic pathologies and whether it can distinguish

335 between different forms of pancreatic cancer and/or pancreatitis. 
Using human and mouse tissue panels, fetal and adult human pancreas and human endocrine cell transplant models, we demonstrated that miR-216a is specific to pancreatic tissue.

338 Therefore, a global miR-216a KO mouse was used to investigate the role of miR-216a in both endocrine and exocrine compartments in vivo. Islets isolated from the miR-216a $\mathrm{KO}$ mice were smaller and secreted less insulin than control islets. Similarly, analysis of pancreatic

341 tissue confirmed the presence of smaller islets and reduced $\beta$-cell mass in the miR-216a KO

342 adult mice, whether on normal or high fat diet. Interestingly, pancreata from the miR-216a

343 KO newborn mice had a trend towards increased islet size. Islet growth is size-dependent

344 during development, with preferential expansion of smaller islets and fission of large

345 interconnected islet-like structures occurring most actively at approximately three weeks of 346 age at the time of weaning ${ }^{23}$. As we observed a major difference in islet size in the miR-216a

347 KO mice postnatally, our data supports a postnatal role for miR-216a in islet cell expansion 348 and migration. Indeed, we show miR-216a increases cell migration and proliferation in vitro.

349 Further studies are required to examine whether miR-216a can also impact cell fission.

Levels of miR-216a were regulated by TGF- $\beta$ signalling and deletion of miR-216a led to an

352 increase in Smad7 levels in the miR-216a KO islets. This result is in alignment with published 353 data showing that forced expression of miR-216a increases epithelial to mesenchymal

354 transition (EMT) and migration with metastatic ability in epithelial hepatic cellular carcinoma 355 (HCC) cells by targeting Pten and Smad $7^{28}$. Although we did not observe any differences in 356 Pten transcript or protein levels (not shown), we found an increase in Smad7 levels in islets of 357 miR-216a KO mice. We also observed changes in the expression of genes involved in EMT 358 and migration in MIN6 and PANC-1 cells. Lack of Pten regulation by miR-216a in our study 359 could be explained by differences in target gene selection under physiological vs.

360 overexpression conditions such as the one used in the aforementioned studies. Alternatively, 
361 the selection of studied cell types (pancreas vs. HCC cells) could lead to differences in miRNA targets.

Analysis of RNA-seq results showed that cell cycle pathways were the most significantly enriched GO term in the miR-216a KO mice. Similarly, DNA replication, nuclear division, and cell proliferation were among the most altered biological processes. As miRNAs affect the expression of multiple genes, identifying signalling pathways targeted by miRNAs rather than minor changes in individual genes are more meaningful to interpret the role of miRNAs in the cellular and physiological context. By opting to isolate pancreatic RNA from one-day old pups, we focused on the earliest biological changes that occurred in the miR-216a KO mice postnatally, thereby revealing the potential causal mechanisms for the observed

372 phenotype. Based on the expression of miR-216a in the acinar tissue as well as on the altered pathways in miR-216a KO pancreata, we hypothesized miR-216a may have a functional role in pancreatic cancer initiation. Our data show that deletion of miR-216 in the presence of oncogenic signals reduces incidence of neoplastic lesions in pancreatic cancer.

Cancer is characterized by uncontrolled proliferation resulting from aberrant activity of cell cycle proteins, thus many cell cycle regulators are important targets in cancer therapy ${ }^{51}$. A hallmark genetic event in PDAC is loss of the CDKN2A/2B tumor suppressor locus ${ }^{52}$ which encodes Cdk4/6 inhibitors that are particularly important for KRAS driven tumors such as

381 PDAC ${ }^{53,54}$. Our RNA-seq analysis identified downregulation of many cell cycle and 382 proliferation genes such as Cdk1, Cdk4 and Pcna in the miR-216a KO mice and we found reduced PanIN formation in the presence of oncogenic KRAS, both of which suggest partial protection from pancreatic cancer initiation. TGF- $\beta$ signalling pathway is another important and commonly deregulated signalling pathway in pancreatic carcinomas ${ }^{55}$. Activation of 
their target genes involved in cell cycle progression ${ }^{55}$. We showed that miR-216a levels are regulated by TGF- $\beta$ signalling and miR-216a deletion increases levels of Smad7, which is a known inhibitor of cell cycle progression. Our results support a model whereby TGF- $\beta$ induced miR-216 directly reduces Smad7 levels and increases the expression of genes

391 involved in cell cycle progression which in the presence of oncogenic mutations such as

392 KRAS give rise to PanIN lesions. Whether there are other direct miR-216a targets mitigating this effect needs further evaluation. MiRNA based therapies are becoming more attractive due

394 to their stability, sequence specificity and relative ease of miRNA synthesis ${ }^{56}$. Recently, 395 engineered exosomes carrying short hairpin RNA specific to oncogenic $\mathrm{Kras}^{\mathrm{G} 12 \mathrm{D}}$, targeted 396 oncogenic KRAS with an enhanced efficacy and suppressed cancer in multiple mouse models 397 of pancreatic cancer ${ }^{57}$. It remains to be investigated whether inhibition of miR-216a either 398 alone or in combination with KRAS can lead to a greater attenuation of tumor growth and an 399 increase in overall survival in PDAC.

In summary, our results reveal for the first time a pancreas-specific miRNA (miR-216a) with 402 physiological roles in both endocrine and exocrine cells, and show how dysregulation of miR403 216a levels affect $\beta$-cell mass and pancreatic cancer initiation. miR-216a is upregulated by 404 TGF- $\beta$ signalling and pancreata of miR-216a KO mice harbor reduced size islets with reduced $405 \beta$-cell mass. miR-216a regulates the expression of genes involved in cell cycle progression 406 and proliferation and deletion of miR-216a reduces the incidence of neoplastic lesions in 407 KRAS mutant mice. Our findings offer insights into how islet size and $\beta$-cell mass are 408 regulated by a pancreas-specific miRNA and offer potential intervention opportunities to slow $409 \beta$-cell death in diabetes. Furthermore, it opens up new possibilities to study the signalling 410 pathways altered in PDAC patients. Finally, given the specificity of miR-216a for the 411 pancreas, it provides biomarker opportunities to evaluate pancreatic disease status or 412 progression. 


\section{Materials and Methods}

Generation of MiR-216a Knockout Mice. The miR-216a KO ES cell line was generated by the Wellcome Trust Sanger Institute ${ }^{22}$ and the $m i R-216 a-/-(m i R-216 a \mathrm{KO})$ mouse line was generated by the Centre for Phenogenomics in Toronto, Canada. Briefly, two frozen miR216a KO ES cell (JM8A3 derived from C57BL/6N) clones (4H7 and 4H9) were purchased from the Mutant Mouse Resource and Research Center (USA) and were expanded and aggregated with diploid CD1 embryos. Coat color chimerism was scored and chimeras were bred with albino B6N (B6N-Tyr $\left.{ }^{c-B r d} / \mathrm{BrdCrCrl}\right)$ females to test germline transmission.

Successful germline transmission was confirmed with TaqMan qPCR of DNA prepared from tail clips, using the following primers in two separate reactions (KO and $\mathrm{WT}$ allele). The KO allele assay yields a 125 bp product. Forward: 5`AGT TCC TAT TCC GAA GTT CCT ATT C 3`. Reverse: 5`AGA GGT TGA GGA CAG ACA GTA 3`. Probe (sense); TGG TCA TAG CTG TTT CCT GAA CAC CA. Cycling conditions: $98^{\circ} \mathrm{C}, 30 \mathrm{~s} ; 40$ cycles of $98^{\circ} \mathrm{C}, 5 \mathrm{~s} ; 56^{\circ} \mathrm{C}$, 10s. The WT allele assay yields a 135 bp product. Forward: 5 'GGC TAT GAG TTG GTT TA 3`. Reverse: $5 `$ GGA AAT TGC TCT GTT TAG 3`. Probe (antisense): CTG TGA GGA ATG ATA GGG AC. Cycling conditions: $95^{\circ} \mathrm{C}, 30 \mathrm{~s} ; 35$ cycles of $95^{\circ} \mathrm{C}, 5 \mathrm{~s} ; 59^{\circ} \mathrm{C}, 10 \mathrm{~s}$. Reactions were performed using the iTaq Universal Probes Supermix (Bio-Rad \#1725131, Hercules, California, USA) on the CFX96 Touch Thermal Cycler (Bio-Rad 1855195). Both probes were labelled with 6'-FAM.

MiR-216a-/- mice were crossed with WT C57BL/6 mice for at least 3 generations before use in experiments and maintained on a C57BL/6 background obtained from the University of British Columbia Animal Care Facility. In all experiments, aged-matched littermates of miR216a KO mice were used as controls. Mice were fed a chow diet (2918, Research Diets) and were housed with a 12-h:12-h light-dark cycle with constant temperature and humidity and ad libitum access to food and water. Body weight and blood glucose were measured after a 4hour morning fast. Blood was collected from the saphenous vein with heparin coated capillary 
441 tubes. All procedures with animals were approved by the University of British Columbia

442 Animal Care Committee and carried out in accordance with the Canadian Council on Animal

443 Care guidelines. For high-fat-diet (HFD) studies, C57BL/6 wild-type littermates and miR-

444 216a KO mice were fed a 60\% HFD diet (D12492i, Research Diets, Cedarlane, Burlington,

445 Canada) starting at 6-8 weeks of age for 8 weeks. LSL-KrasG12D ${ }^{58,59}\left(\operatorname{Kras}^{\mathrm{G} 12 \mathrm{D}}\right)$ and

446 PtflaCre ${ }^{60}$ have been described previously ${ }^{35}$ and were maintained on a mixed background.

447 Leptin knock-out rats ${ }^{31}$ and kidney capsule grafts obtained from mice and rats implanted with 448 pancreatic progenitor cells ${ }^{21}$ are described elsewhere.

449 Metabolic Assessments. All metabolic analyses were performed in conscious mice that were 450 restrained during blood sampling. Blood glucose values were determined with a OneTouch 451 Ultra 2 glucometer (LifeScan, Inc., Burnaby, Canada) measured from saphenous vein blood.

452 Fasting (4 hours) glucose and body weight were monitored weekly. For glucose tolerance 453 tests with chow-diet or HFD fed mice, 6 hour fasted mice were given $2 \mathrm{~g} / \mathrm{kg}$ glucose either by 454 intraperitoneal injection or oral gavage, and blood was collected into heparin-coated capillary 455 tubes at indicated times following glucose administration. For insulin tolerance tests, 4 hour 456 fasted mice were injected intraperitoneally with $0.75 \mathrm{U} / \mathrm{kg}$ insulin (Novolin ge Toronto, Novo 457 Nordisk Canada, Mississauga, Canada), with glucose measures at indicated times following 458 glucose administration.

459 Islet Isolation. Mouse islets were isolated as previously described ${ }^{61}$ using Type XI 460 collagenase (1000 units/mL; \#C7657, Sigma-Aldrich, St. Louis, MO). Following digestion 461 and filtration, islets were picked with a pipette in three rounds to $>95 \%$ purity. Islets were 462 cultured overnight in RPMI-1640 (Sigma-Aldrich, St. Louis, MO) supplemented with 10\% 463 FBS (\#F1051, Sigma-Aldrich, St. Louis, MO), 100 units/mL penicillin and $100 \mu \mathrm{g} / \mathrm{mL}$ 464 streptomycin. For glucose stimulated insulin secretion assays, the next day after isolation 30 465 islets per mouse were placed in 24-well plates with KRBB buffer (129 mM NaCl, $4.8 \mathrm{mM}$ $466 \mathrm{KCl}, 1.2 \mathrm{mM} \mathrm{MgSO} 4,1.2 \mathrm{mM} \mathrm{KH}_{2} \mathrm{PO}_{4}, 2.5 \mathrm{mM} \mathrm{CaCl}_{2}, 5.0 \mathrm{mM} \mathrm{NaHCO} 3,10 \mathrm{mM}$ HEPES, 
$0.5 \%$ BSA, pH: 7.4) supplemented with $2.8 \mathrm{mM}$ Glucose (low-Glucose). After one hour of incubation at $37^{\circ} \mathrm{C}$, media was discarded. Islets were then serially placed in low Glucose $(2.8$ mM Glucose) KRBB buffer, high Glucose (16.7 mM) KRBB buffer and $20 \mathrm{mM} \mathrm{KCl}$ for 1 hour at $37^{\circ} \mathrm{C}$. At the end of each incubation media was collected, centrifuged and stored at $20^{\circ} \mathrm{C}$. Following the last media collection, islets were lysed in $0.18 \mathrm{M} \mathrm{HCl} / 70 \%$ ethanol, homogenized, then incubated again at $-20^{\circ} \mathrm{C}$ overnight. Following centrifugation, the aqueous solution was neutralized 1:2 with $1 \mathrm{M}$ Tris, $\mathrm{pH}$ 7.5.

Cell Culture. The INS-1 rat insulinoma cell line was cultured in RPMI-1640 containing 11.2 $\mathrm{mM}$ glucose and $2 \mathrm{mM}$ L-glutamine. The medium was supplemented with $10 \%$ fetal bovine serum, 1 mM sodium pyruvate (\#S8636, Sigma-Aldrich), 10 mM HEPES, 50 MM 2mercaptoethanol (Sigma Aldrich), $100 \mathrm{U} / \mathrm{mL}$ penicillin (Sigma Aldrich), and $100 \mu \mathrm{g} / \mathrm{mL}$ streptomycin (Sigma Aldrich). PANC-1 cells were cultured in DMEM media (Life Technologies) containing $4 \mathrm{mM}$ L-glutamine, $4500 \mathrm{mg} / \mathrm{L}$ glucose, $1 \mathrm{mM}$ sodium pyruvate, and $1500 \mathrm{mg} / \mathrm{L}$ sodium bicarbonate supplemented with $10 \%$ fetal bovine serum, $100 \mathrm{U} / \mathrm{ml}$ penicillin, and $100 \mu \mathrm{g} / \mathrm{ml}$ streptomycin. EndoC- $\beta \mathrm{H} 1$ cells provided by (Drs. R Scharfmann, and P. Ravassard) were cultured on ECM-fibronectin-coated ( $1 \%$ and $2 \mu \mathrm{g} / \mathrm{ml}$, respectively) (Sigma-Aldrich) culture wells and maintained in DMEM (Sigma Aldrich) that contained 5.6 $\mathrm{mM}$ glucose, 2\% BSA fraction V (Roche Diagnostics), $50 \mu \mathrm{M}$ 2-mercaptoethanol, $10 \mathrm{mM}$ nicotinamide (Sigma-Aldrich), $5.5 \mu \mathrm{g} / \mathrm{ml}$ transferrin (Sigma-Aldrich), $6.7 \mathrm{ng} / \mathrm{ml}$ selenite (Sigma-Aldrich), $100 \mathrm{U} / \mathrm{ml}$ penicillin, and $100 \mu \mathrm{g} / \mathrm{ml}$ streptomycin. For transfections, cells were plated on 6-well plates (unless stated otherwise), and the next day 50-70\% confluent cells were transfected with miR-216a (50 nM) and miRNA controls (50 nM) using RNAimax (Life Technologies) following manufacturer`s instructions. To control for tranfection effects, at least 3 wells were left untransfected. The protocol for differentiating CA1S human ES cells into pancreatic endocrine cells was described elsewhere ${ }^{19}$. 
493 Cloning. miRNA-GFP expression vectors were generated by initially creating a EGFP

494

495 expression vector, pScamp EF1a-EGFP, which contains the 5' end of the human EF1A gene (a genomic PCR amplicon containing $1407 \mathrm{bp}$ of proximal promoter, exon 1, intron 1, and the UTR of exon 2), followed by the EGFP ORF and SV40 poly(A) signal, all cloned into pBluescript. This was subsequently modified into a "miRtron" expression vector, pScamp EF1a-premir-216a-EGFP, by removing 450 bp of the middle EF1A intron with restriction endonucleases BfuAI and XhoI, and replacing it with a compatible BsmBI-SalI restriction fragment of a 575-bp amplicon* consisting of the full hsa-premir-216a sequence, flanked on either side by roughly 200 bp of endogenous genomic sequences. Cells transfected with this plasmid produce a chimeric EF1A-EGFP mRNA that gets translated into a fluorescent protein, while the excised intron is processed into mature hsa-miR-216a.* miRtron hsapremir-216a cloning primers (BsmBI and XhoI 5' overhangs are underlined). Forward: 5' gggcacacaCGTCTCGACGCAGATTATACTTTTATGACATTACATGCAATATAGC 3'; Reverse: 5' cacacaGTCGACCCAAGTAGCACTGAAGGAGCG 3'.

Pancreas Immunohistochemistry and Histology. Pancreata were fixed overnight in 4\% paraformaldehyde (PFA) and then stored in $70 \% \mathrm{EtOH}$ prior to paraffin embedding and sectioning (5 $\mu \mathrm{m}$ thickness; Wax-it Histology Services; Vancouver, BC). Immunofluorescent staining was performed as previously described ${ }^{62}$. Briefly, slides were deparaffinized in xylene and hydrated by graded ethanol washes. Slides were then washed in phosphatebuffered saline (PBS) followed by $10-15 \mathrm{~min}$ incubation in $10 \mathrm{mM}$ sodium citrate/ $0.05 \%$ Tween 20, pH 6.0 at $95^{\circ} \mathrm{C}$. Slides were incubated with DAKO Protein Block Serum-Free (Agilent Technologies, Inc, Santa Clara, CA) at room temperature for 10 minutes and then with the primary antibodies diluted in Dako Antibody Diluent (Agilent Technologies, Inc.) overnight at $4{ }^{\circ} \mathrm{C}$. The following primary antibodies were used: insulin (Cell Signalling, \# 
3014 at 1:200), glucagon (Sigma Aldrich, \#G2654 at 1:1000), synaptophysin (Monosan,

518 \#MON9013 at 1:10), and PCNA (BD Transduction, \#610665 at 1:100). The next day slides

519 were serially washed with PBS and were incubated in appropriate Alexa Fluor 488 or 594

520 secondary antibodies (Thermo Fisher Scientific, Waltham, MA) diluted in Dako Antibody

521 Diluent. Following serial PBS washes, slides were coverslipped with VECTASHIELD

522 HardSet Mounting Medium with DAPI (Vector Laboratories, Burlingame, CA). Images were

523 captured using a ImageXpress Micro ${ }^{\mathrm{TM}}$ Imaging System and analyzed using MetaXpress

524 5.3.0.5 Software (Molecular Devices Corporation, Sunnyvale, CA, USA). $\beta$-cell mass was

525 analyzed in three pancreas sections per mouse, at least $200 \mu \mathrm{m}$ apart, on insulin-labeled

526 sections. Islet size was quantified as the synaptophysin-positive area per islet. For the $\alpha$-cell

527 analysis, glucagon-immunoreactive cells were counted using the ImageJ Cell Counter tool.

528 Only islets with visible DAPI stained nuclei and at least 40 cells and 10 or more non- $\beta$ cells

529 were used to determine periphery or core localization of $\alpha$-cells. $\alpha$-cells were considered to be

530 in the periphery of the islet if they were within 2 outermost cell layers of the islet or the core

531 if they were deeper than the 2 outermost cell layers of the islet. For the islet circularity

532 analysis, islets stained with synaptophysin and DAPI were used. Only islets with at least 40

533 cells and 10 or more non- $\beta$ cells were used to determine islet circularity. All images were

534 converted to 8-bit and non-islet nuclei were erased using ImageJ outline and clear function.

535 Islet circularity was determined using Analyze Particles with threshold set until the entire area

536 of islet was filled. H\&E staining and Alcian blue staining on pancreatic sections were

537 performed by Wax-it Histology Services Inc. (Vancouver, Canada).

538 RNA Isolation and Quantitative RT-PCR. Tissues were homogenized with an Ultra-Turrax

539 and total RNA was isolated using the miRCURY RNA isolation kit (Exiqon, U.S.A) as per

540 the manufacturer's instructions including a DNAse (Life Technologies) treatment step.

541 mRNA was reverse transcribed with iScript cDNA Synthesis Kit (Bio-Rad Laboratories, 
542 Hercules, CA) and quantitative RT-PCR was performed using Ssofast EvaGreen Supermix

543 (Bio-Rad). Primer sequences to amplify Insulin, Pdx1, Nkx6.1, and Hprt transcripts were

544 described previously ${ }^{63}$. Primer sequences for Glucagon were Forward: 5

545 CGCAGGCACGCTGATG 3` Reverse: 5`ACGAGATGTTGTGAAGATGGTTG 3`. A

546 human RNA panel was purchased from ThermoFisher Scientific (\#AM6000). miRNA was

547 reverse transcribed with a Universal cDNA synthesis kit (Exiqon, U.S.A) and qRT-PCR was

548 performed using SYBR Green master mix (Exiqon, U.S.A) with LNA-based miRNA primers

549 (Exiqon, U.S.A). Relative values were calculated by the quantified by the $2^{-\Delta \Delta C T}$ method.

550 RNA from the pancreata of 1-day old mice was isolated using a protocol specific for

551 pancreatic RNA isolations ${ }^{64}$.

552 In situ Hybridization. Human fetal pancreata were kindly provided by Dr. Renian Wang,

553 University of Western Ontorio, London, Canada and were described elsewhere ${ }^{20}$. Human

554 adult pancreas was provided by the Irving K. Barber Human Islet Isolation Laboratory

555 (Vancouver, British Columbia) with consent to use for research purposes. All samples were

556 fixed overnight in 4\% PFA, embedded in paraffin and sectioned (5 $\mu \mathrm{m}$ thickness; Wax-it

557 Histology Services; Vancouver, BC). Slides were de-paraffinized with three consecutive

558 xylene washes, rehydrated with graded ethanol washes $(100 \% \times 3,95 \%, 70 \%$, each 5

559 minutes), and washed in diethylpyrocarbonate (DEPC)-treated water. In situ hybridization

560 was carried out with a IsHyb In Situ Hybridization kit (Biochain, San Francisco, California).

561 Sections were fixed with 4\% PFA for 20 minutes, washed twice with DEPC-treated PBS, and

562 treated with $10 \mu \mathrm{g} / \mathrm{mL}$ Proteinase K (Sigma Aldrich) at $37^{\circ} \mathrm{C}$ for 15 minutes. Slides were

563 washed with DEPC-treated PBS, fixed again with PFA for 15 minutes, and washed with

564 DEPC-treated water. Sections were incubated for 4 hours at $50^{\circ} \mathrm{C}$ in pre-hybridization

565 solution (Biochain). Afterwards, pancreatic sections were incubated with DIG-labeled hsa-

566 miR-216a miRCURY LNA detection probe (\#38495-15, Exiqon) or control scrambled 
miRNA probe (\#99004-15, Exiqon) at $0.25 \mathrm{ng} / \mu \mathrm{L}$ in hybridization solution (Biochain) for 14

568 hours at $45^{\circ} \mathrm{C}$. Then, slides were washed in SSC buffer (Biochain) as follows: 2X SSC buffer, $5692 \times 10 \mathrm{~min}, 45^{\circ} \mathrm{C} ; 1.5 \mathrm{X} \mathrm{SSC}$ buffer, $1 \times 10 \mathrm{~min}, 45^{\circ} \mathrm{C} ; 2 \mathrm{x} \mathrm{SSC}$ buffer, $2 \times 20$ minutes, $37^{\circ} \mathrm{C}$. After

570 washing steps, sections were incubated with $1 \mathrm{X}$ blocking solution (Biochain) in PBS for 1

571 hour. Slides were incubated overnight with alkaline-phosphate conjugated anti-digoxinogen

572 antibody (diluted 1:500 in PBS) (Biochain) at $4^{\circ} \mathrm{C}$. The following day, slides were washes

573 three times with PBS for 10 minutes, twice with alkaline phosphatase buffer (Biochain) for 5

574 minutes, and incubated with nitro-blue tetrazolium chloride (NBT) and 5-bromo-4-chloro-3'-

575 indolyphosphate p-toluidine salt (BCIP) solution $(6.6 \mu \mathrm{L}$ NBT and $3.3 \mu \mathrm{L}$ BCIP were diluted

576 in $1 \mathrm{~mL}$ alkaline phosphatase buffer) (Biochain) for 20 hours at room temperature. Slides

577 were scanned using a ScanScope CS system (Aperio; Vista, CA).

578 Assays. Insulin was measured in plasma, islets and cell culture media using a Mouse

579 Ultrasensitive Insulin ELISA (ALPCO, Salem, NH). Proinsulin was measured from plasma

580 collected from cardiac blood using Rat/Mouse Proinsulin ELISA (Mercodia, Sweden). To

581 perform migration assay with cultured cell lines, PANC-1 cells were transfected with the

582 miR-216a and control scrambled miRNA mimetics (Dharmacon, Lafayette, CO) and 24 hours

583 later, seeded on trans-well migration chambers (Trevigen, Gaithersburg, MD) in media

584 without FBS. Cells were allowed to migrate for 16 hours and the number of cells transversing

585 the boyer chamber was quantified by incubating the cells in the bottom chamber with Calcein-

586 AM for one hour and measuring the fluorescence at $485 \mathrm{~nm}$ excitation, $520 \mathrm{~nm}$ emission with

587 a Tecan Plate Reader. For the XTT (2,3-bis-(2-methoxy-4-nitro-5-sulfophenyl)-2H-

588 tetrazolium-5-carboxanilide) assay, cells were transfected with miR-216a and the control

589 miRNAs and an XTT assay was performed 3 days post-transfection in 96-well plates. XTT

590 (Life Technologies) was dissolved in pre-warmed $37^{\circ} \mathrm{C}$ cell culture media at $1 \mathrm{mg} / \mathrm{mL}$ and

591 stock Phenazine methosulfate (PMS) solution was prepared in PBS at $10 \mathrm{mM}$. PMS was 
mixed with the XTT solution immediately before labeling the cells and $25 \mu \mathrm{L}$ of XTT/PMS

solution was directly added to each well containing $100 \mu \mathrm{L}$ cell culture media. Cells were

594 incubated for two hours at $37^{\circ} \mathrm{C}$ in a $\mathrm{CO}_{2}$ incubator. Absorbance was read at $450 \mathrm{~nm}$ using a

595 Tecan Plate Reader. For live cell imaging, INS-1 cells seeded on 96-well plates were

596 transfected with control or miR-216a expressing plasmids or left untreated. Two days after

597 transfection, cells were incubated with $50 \mathrm{ng} / \mathrm{mL}$ Hoechst and 1:500 diluted Alexa647

598 annexinV 30 min prior to imaging. TNF- $\alpha$, IFN- $\Upsilon$ and IL-1 $\beta$ (10 ng/mL each) was added to

599 media and cells were imaged every 2 hours at $37^{\circ} \mathrm{C}$ and $5 \% \mathrm{CO}_{2}$ in an ImageXpress Micro ${ }^{\mathrm{TM}}$

600 (Molecular Devices).

601 RNA Sequencing and Analysis. RNA sequencing was performed by the Biomedical

602 Research Center Genomics facility at the University of British Columbia, Vancouver, Canada.

603 Sample quality control was assessed using an Agilent 2100 Bioanalyzer. Qualifying samples

604 (samples with RNA integrity numbers $>8$ ) were then prepared following the standard

605 protocol for the NEBnext Ultra ii Stranded mRNA (New England Biolabs). Sequencing was

606 performed on the Illumina NextSeq 500 with Paired End $42 \mathrm{bp} \times 42 \mathrm{bp}$ reads. Sequencing data

607 were demultiplexed using Illumina's bcl2fastq2.

608 Fastq files were retrieved from Illumina Basespace and aligned with salmon ${ }^{65}$ (version 0.13.1)

609 to the most current Ensembl Mus Musculus genome (as of 2019-05-08) ${ }^{66}$ using the gcBias,

610 validateMappings, and rangeFactorizationBins (with 4 as the binning parameter) options.

611 Quality of the Fastq files was assessed using FastQC ${ }^{67}$ (version 0.11.8). All fastq files passed

612 quality control. All further analyses were performed in R (version 3.6.0) ${ }^{68}$. Counts were

613 imported using the tximport package (version 1.12.0) ${ }^{69}$ and the biomaRt package (version

$6140.8 \cdot 0)^{70,71}$. Analysis of differentially expressed genes was performed using the DESeq2

615 (version 1.24.0 $)^{72}$. Genes with less than 5 counts in 2 samples or fewer were dropped from the 616 analysis. Gene Ontology analysis was performed on genes with an IQR greater than 0.5 across 
617 all samples and an adjusted $\mathrm{p}$ value $<0.05$ (adjusted by Benjamini-Hochberg method)

618 between wild type and control mice. Significantly enriched terms for Biological Process,

619 Cellular Components, and Molecular Functions were identified using the categoryCompare

620 package (version 1.28.0) ${ }^{73}$ and visualized using Cytoscape via the RCy3 package (version

$6212.4 .0)^{74}$. Further KEGG network analyses were performed using the gage (version 2.34.0 $)^{75}$

622 and pathview (version 1.24.0) packages $^{76}$. Finally, GO terms were summarized using the

623 REViGO methodology ${ }^{77}$ and plotted using the treemap (version 2.4.2) package ${ }^{78}$. All R

624 scripts and data are available upon request.

625 Statistical Analyses. Statistical analyses were performed using GraphPad Prism 7, with

626 significance defined as $\mathrm{p}<0.05$. Unless specified in the figure legend, student`s t-tests were

627 used for normally distributed data (two-tailed, unpaired). Bonferroni correction was used to

628 correct for multiple comparisons, where applicable. Data are represented by bar plots with

629 individual values indicated, individual values only, or line graphs. Results show mean \pm SEM. 


\section{Acknowledgements}

631 We thank Dr. Anna D'Souza for providing islets from Leptin knock-out rats. T.J.K. gratefully 632 acknowledges funding from JDRF and the Canadian Institutes for Health Research for this research.

633 S.E. is a recipient of a JDRF advanced postdoctoral fellowship. We would also like to thank Dr. Ziliang 634 Ao and Dr. Garth L. Warnock from the Irving K. Barber Human Islet Isolation Laboratory (Vancouver, $635 \mathrm{BC}$ ) for providing human islets.

636

637 Disclosure Statement: The authors have nothing to disclose. 


\section{References}

1 Brissova, M. et al. Assessment of human pancreatic islet architecture and composition by laser scanning confocal microscopy. J Histochem Cytochem 53, 1087-1097, doi:10.1369/jhc.5C6684.2005 (2005).

2 American Diabetes, A. Diagnosis and classification of diabetes mellitus. Diabetes Care 33 Suppl 1, S62-69, doi:10.2337/dc10-S062 (2010).

3 Storz, P. Acinar cell plasticity and development of pancreatic ductal adenocarcinoma. Nat Rev Gastroenterol Hepatol 14, 296-304, doi:10.1038/nrgastro.2017.12 (2017).

4 Bartel, D. P. MicroRNAs: genomics, biogenesis, mechanism, and function. Cell 116, 281-297 (2004).

5 Carthew, R. W. \& Sontheimer, E. J. Origins and Mechanisms of miRNAs and siRNAs. Cell 136, 642-655, doi:10.1016/j.cell.2009.01.035 (2009).

6 Godard, P. \& van Eyll, J. Pathway analysis from lists of microRNAs: common pitfalls and alternative strategy. Nucleic Acids Res 43, 3490-3497, doi:10.1093/nar/gkv249 (2015).

$7 \quad$ Akhtar, M. M., Micolucci, L., Islam, M. S., Olivieri, F. \& Procopio, A. D. Bioinformatic tools for microRNA dissection. Nucleic Acids Res 44, 24-44, doi:10.1093/nar/gkv1221 (2016).

8 Londin, E. et al. Analysis of 13 cell types reveals evidence for the expression of numerous novel primate- and tissue-specific microRNAs. Proc Natl Acad Sci U S A 112, E1106-1115, doi:10.1073/pnas.1420955112 (2015).

9 Chiang, H. R. et al. Mammalian microRNAs: experimental evaluation of novel and previously annotated genes. Genes Dev 24, 992-1009, doi:10.1101/gad.1884710 (2010).

10 Lynn, F. C. et al. MicroRNA expression is required for pancreatic islet cell genesis in the mouse. Diabetes 56, 2938-2945, doi:10.2337/db07-0175 (2007).

11 Mandelbaum, A. D. et al. Dysregulation of Dicer1 in beta cells impairs islet architecture and glucose metabolism. Exp Diabetes Res 2012, 470302, doi:10.1155/2012/470302 (2012).

12 Kalis, M. et al. Beta-cell specific deletion of Dicer1 leads to defective insulin secretion and diabetes mellitus. PLoS One 6, e29166, doi:10.1371/journal.pone.0029166 (2011).

13 Martinez-Sanchez, A., Nguyen-Tu, M. S. \& Rutter, G. A. DICER Inactivation Identifies Pancreatic beta-Cell "Disallowed" Genes Targeted by MicroRNAs. Mol Endocrinol 29, 1067-1079, doi:10.1210/me.2015-1059 (2015).

14 Wang, Y. J. et al. Dicer is required for maintenance of adult pancreatic acinar cell identity and plays a role in Kras-driven pancreatic neoplasia. PLoS One 9, e113127, doi:10.1371/journal.pone.0113127 (2014).

15 Niehrs, C. \& Pollet, N. Synexpression groups in eukaryotes. Nature 402, 483-487, doi:10.1038/990025 (1999).

16 Sun, K. \& Lai, E. C. Adult-specific functions of animal microRNAs. Nat Rev Genet 14, 535-548, doi:10.1038/nrg3471 (2013).

17 van Rooij, E. et al. A signature pattern of stress-responsive microRNAs that can evoke cardiac hypertrophy and heart failure. Proc Natl Acad Sci U S A 103, 18255-18260, doi:10.1073/pnas.0608791103 (2006).

18 Esquela-Kerscher, A. \& Slack, F. J. Oncomirs - microRNAs with a role in cancer. Nat Rev Cancer 6, 259-269, doi:10.1038/nrc1840 (2006).

19 Bruin, J. E. et al. Characterization of polyhormonal insulin-producing cells derived in vitro from human embryonic stem cells. Stem Cell Res 12, 194-208, doi:10.1016/j.scr.2013.10.003 (2014). 
69020 Riedel, M. J. et al. Immunohistochemical characterisation of cells co-producing

691

692

693

694

695

696

697

698

699

700

701

702

703

704

705

706

707

708

709

710

711

712

713

714

715

716

717

718

719

720

721

722

723

724

725

726

727

728

729

730

731

732

733

734

735

736

737

738

739

740 insulin and glucagon in the developing human pancreas. Diabetologia 55, 372-381, doi:10.1007/s00125-011-2344-9 (2012).

21 Bruin, J. E. et al. Accelerated Maturation of Human Stem Cell-Derived Pancreatic Progenitor Cells into Insulin-Secreting Cells in Immunodeficient Rats Relative to Mice. Stem Cell Reports 5, 1081-1096, doi:10.1016/j.stemcr.2015.10.013 (2015).

22 Prosser, H. M., Koike-Yusa, H., Cooper, J. D., Law, F. C. \& Bradley, A. A resource of vectors and ES cells for targeted deletion of microRNAs in mice. Nat Biotechnol 29, 840-845, doi:10.1038/nbt.1929 (2011).

23 Jo, J. et al. Formation of pancreatic islets involves coordinated expansion of small islets and fission of large interconnected islet-like structures. Biophys $J$ 101, 565-574, doi:10.1016/j.bpj.2011.06.042 (2011).

24 Miettinen, P. J. et al. Impaired migration and delayed differentiation of pancreatic islet cells in mice lacking EGF-receptors. Development 127, 2617-2627 (2000).

25 Greiner, T. U., Kesavan, G., Stahlberg, A. \& Semb, H. Rac1 regulates pancreatic islet morphogenesis. BMC Dev Biol 9, 2, doi:10.1186/1471-213X-9-2 (2009).

26 Ritvos, O. et al. Activin disrupts epithelial branching morphogenesis in developing glandular organs of the mouse. Mech Dev 50, 229-245 (1995).

27 Kato, M. et al. TGF-beta activates Akt kinase through a microRNA-dependent amplifying circuit targeting PTEN. Nat Cell Biol 11, 881-889, doi:10.1038/ncb1897 (2009).

28 Xia, H., Ooi, L. L. \& Hui, K. M. MicroRNA-216a/217-induced epithelialmesenchymal transition targets PTEN and SMAD7 to promote drug resistance and recurrence of liver cancer. Hepatology 58, 629-641, doi:10.1002/hep.26369 (2013).

29 Xu, J., Lamouille, S. \& Derynck, R. TGF-beta-induced epithelial to mesenchymal transition. Cell Res 19, 156-172, doi:10.1038/cr.2009.5 (2009).

30 LaPierre, M. P. \& Stoffel, M. MicroRNAs as stress regulators in pancreatic beta cells and diabetes. Mol Metab 6, 1010-1023, doi:10.1016/j.molmet.2017.06.020 (2017).

31 D'Souza A, M., Asadi, A., Johnson, J. D., Covey, S. D. \& Kieffer, T. J. Leptin deficiency in rats results in hyperinsulinemia and impaired glucose homeostasis. Endocrinology 155, 1268-1279, doi:10.1210/en.2013-1523 (2014).

32 Poy, M. N. et al. A pancreatic islet-specific microRNA regulates insulin secretion. Nature 432, 226-230, doi:10.1038/nature03076 (2004).

33 Erener, S., Mojibian, M., Fox, J. K., Denroche, H. C. \& Kieffer, T. J. Circulating miR375 as a biomarker of beta-cell death and diabetes in mice. Endocrinology 154, 603608, doi:10.1210/en.2012-1744 (2013).

34 Erener, S., Marwaha, A., Tan, R., Panagiotopoulos, C. \& Kieffer, T. J. Profiling of circulating microRNAs in children with recent onset of type 1 diabetes. JCI Insight 2 , e89656, doi:10.1172/jci.insight.89656 (2017).

35 Kopp, J. L. et al. Identification of Sox9-dependent acinar-to-ductal reprogramming as the principal mechanism for initiation of pancreatic ductal adenocarcinoma. Cancer Cell 22, 737-750, doi:10.1016/j.ccr.2012.10.025 (2012).

36 Guerra, C. et al. Chronic pancreatitis is essential for induction of pancreatic ductal adenocarcinoma by K-Ras oncogenes in adult mice. Cancer Cell 11, 291-302, doi:10.1016/j.ccr.2007.01.012 (2007).

37 Hezel, A. F., Kimmelman, A. C., Stanger, B. Z., Bardeesy, N. \& Depinho, R. A. Genetics and biology of pancreatic ductal adenocarcinoma. Genes Dev 20, 1218-1249, doi:10.1101/gad.1415606 (2006).

38 Kanda, M. et al. Presence of somatic mutations in most early-stage pancreatic intraepithelial neoplasia. Gastroenterology 142, 730-733 e739, doi:10.1053/j.gastro.2011.12.042 (2012). 
74139 Hingorani, S. R. et al. Preinvasive and invasive ductal pancreatic cancer and its early detection in the mouse. Cancer Cell 4, 437-450 (2003).

40 Morris, J. P. t., Cano, D. A., Sekine, S., Wang, S. C. \& Hebrok, M. Beta-catenin

41 Zhu, L., Shi, G., Schmidt, C. M., Hruban, R. H. \& Konieczny, S. F. Acinar cells blocks Kras-dependent reprogramming of acini into pancreatic cancer precursor lesions in mice. J Clin Invest 120, 508-520, doi:10.1172/JCI40045 (2010). contribute to the molecular heterogeneity of pancreatic intraepithelial neoplasia. Am J Pathol 171, 263-273, doi:10.2353/ajpath.2007.061176 (2007). Seymour, P. A. et al. SOX9 is required for maintenance of the pancreatic progenitor cell pool. Proc Natl Acad Sci US A 104, 1865-1870, doi:10.1073/pnas.0609217104 (2007).

43 Prevot, P. P. et al. Role of the ductal transcription factors HNF6 and Sox9 in pancreatic acinar-to-ductal metaplasia. Gut 61, 1723-1732, doi:10.1136/gutjnl-2011300266 (2012).

44 Shroff, S. et al. SOX9: a useful marker for pancreatic ductal lineage of pancreatic neoplasms. Hum Pathol 45, 456-463, doi:10.1016/j.humpath.2013.10.008 (2014).

45 Poy, M. N. et al. miR-375 maintains normal pancreatic alpha- and beta-cell mass. Proc Natl Acad Sci U S A 106, 5813-5818, doi:10.1073/pnas.0810550106 (2009).

46 Biton, M. et al. Epithelial microRNAs regulate gut mucosal immunity via epitheliumT cell crosstalk. Nat Immunol 12, 239-246, doi:10.1038/ni.1994 (2011). Kang, W. et al. miR-375 is involved in Hippo pathway by targeting YAP1/TEAD4CTGF axis in gastric carcinogenesis. Cell Death Dis 9, 92, doi:10.1038/s41419-0170134-0 (2018).

48 Goodwin, D. et al. Evaluation of miR-216a and miR-217 as potential biomarkers of acute pancreatic injury in rats and mice. Biomarkers 19, 517-529, doi:10.3109/1354750X.2014.944217 (2014).

49 Szafranska, A. E. et al. MicroRNA expression alterations are linked to tumorigenesis and non-neoplastic processes in pancreatic ductal adenocarcinoma. Oncogene 26, 4442-4452, doi:10.1038/sj.onc.1210228 (2007).

50 Yang, J. Y. et al. MicroRNAs in stool samples as potential screening biomarkers for pancreatic ductal adenocarcinoma cancer. Am J Cancer Res 4, 663-673 (2014).

51 Otto, T. \& Sicinski, P. Cell cycle proteins as promising targets in cancer therapy. Nat Rev Cancer 17, 93-115, doi:10.1038/nrc.2016.138 (2017).

52 Feldmann, G., Beaty, R., Hruban, R. H. \& Maitra, A. Molecular genetics of pancreatic intraepithelial neoplasia. J Hepatobiliary Pancreat Surg 14, 224-232, doi:10.1007/s00534-006-1166-5 (2007).

53 LaPak, K. M. \& Burd, C. E. The molecular balancing act of p16(INK4a) in cancer and aging. Mol Cancer Res 12, 167-183, doi:10.1158/1541-7786.MCR-13-0350 (2014).

54 Schutte, M. et al. Abrogation of the $\mathrm{Rb} / \mathrm{p} 16$ tumor-suppressive pathway in virtually all pancreatic carcinomas. Cancer Res 57, 3126-3130 (1997).

55 Shen, W. et al. TGF-beta in pancreatic cancer initiation and progression: two sides of the same coin. Cell Biosci 7, 39, doi:10.1186/s13578-017-0168-0 (2017).

56 Smith, B., Agarwal, P. \& Bhowmick, N. A. MicroRNA applications for prostate, ovarian and breast cancer in the era of precision medicine. Endocr Relat Cancer 24, R157-R172, doi:10.1530/ERC-16-0525 (2017). Kamerkar, S. et al. Exosomes facilitate therapeutic targeting of oncogenic KRAS in pancreatic cancer. Nature 546, 498-503, doi:10.1038/nature22341 (2017). Tuveson, D. A. et al. Endogenous oncogenic K-ras(G12D) stimulates proliferation and widespread neoplastic and developmental defects. Cancer Cell 5, 375-387 (2004). Johnson, L. et al. Somatic activation of the K-ras oncogene causes early onset lung cancer in mice. Nature 410, 1111-1116, doi:10.1038/35074129 (2001). 
Kawaguchi, Y. et al. The role of the transcriptional regulator Ptf1a in converting intestinal to pancreatic progenitors. Nat Genet 32, 128-134, doi:10.1038/ng959 (2002). Salvalaggio, P. R. et al. Islet filtration: a simple and rapid new purification procedure that avoids ficoll and improves islet mass and function. Transplantation 74, 877-879, doi:10.1097/01.TP.0000028781.41729.5B (2002). Asadi, A., Bruin, J. E. \& Kieffer, T. J. Characterization of Antibodies to Products of Proinsulin Processing Using Immunofluorescence Staining of Pancreas in Multiple Species. J Histochem Cytochem 63, 646-662, doi:10.1369/0022155415576541 (2015).

801

802

803

804

805

806

807

808

809

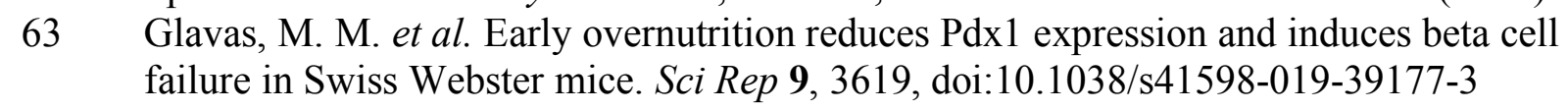
(2019).

64 Azevedo-Pouly, A. C., Elgamal, O. A. \& Schmittgen, T. D. RNA isolation from mouse pancreas: a ribonuclease-rich tissue. J Vis Exp, e51779, doi:10.3791/51779 (2014).

65 Patro, R., Duggal, G., Love, M. I., Irizarry, R. A. \& Kingsford, C. Salmon provides fast and bias-aware quantification of transcript expression. Nat Methods 14, 417-419, doi:10.1038/nmeth.4197 (2017).

66 Zerbino, D. R. et al. Ensembl 2018. Nucleic Acids Res 46, D754-D761, doi:10.1093/nar/gkx1098 (2018).

810 S., A. FastQC: a quality control tool for high throughput sequence data, $<$ http://www.bioinformatics.babraham.ac.uk/projects/fastqc $>$ (2010).

814 for Statistical Computing, Vienna, Austria, <https://www.R-project.org/> (2019). Soneson, C., Love, M. I. \& Robinson, M. D. Differential analyses for RNA-seq: transcript-level estimates improve gene-level inferences. F1000Res 4, 1521, doi:10.12688/f1000research.7563.2 (2015).

70 Durinck, S. et al. BioMart and Bioconductor: a powerful link between biological databases and microarray data analysis. Bioinformatics 21, 3439-3440, doi:10.1093/bioinformatics/bti525 (2005).

71 Durinck, S., Spellman, P. T., Birney, E. \& Huber, W. Mapping identifiers for the integration of genomic datasets with the R/Bioconductor package biomaRt. Nat Protoc 4, 1184-1191, doi:10.1038/nprot.2009.97 (2009).

72 Love, M. I., Huber, W. \& Anders, S. Moderated estimation of fold change and dispersion for RNA-seq data with DESeq2. Genome Biol 15, 550, doi:10.1186/s13059-014-0550-8 (2014).

73 Flight, R. M. et al. categoryCompare, an analytical tool based on feature annotations. Front Genet 5, 98, doi:10.3389/fgene.2014.00098 (2014).

74 Ono, K., Muetze, T., Kolishovski, G., Shannon, P. \& Demchak, B. CyREST: Turbocharging Cytoscape Access for External Tools via a RESTful API. F1000Res 4, 478, doi:10.12688/f1000research.6767.1 (2015). generally applicable gene set enrichment for pathway analysis. BMC Bioinformatics 10, 161, doi:10.1186/1471-2105-10-161 (2009).

76 Luo, W. \& Brouwer, C. Pathview: an R/Bioconductor package for pathway-based data integration and visualization. Bioinformatics 29, 1830-1831, doi:10.1093/bioinformatics/btt285 (2013).

77 Supek, F., Bosnjak, M., Skunca, N. \& Smuc, T. REVIGO summarizes and visualizes long lists of gene ontology terms. PLoS One 6, e21800, doi:10.1371/journal.pone.0021800 (2011). 


\section{Figure 1}
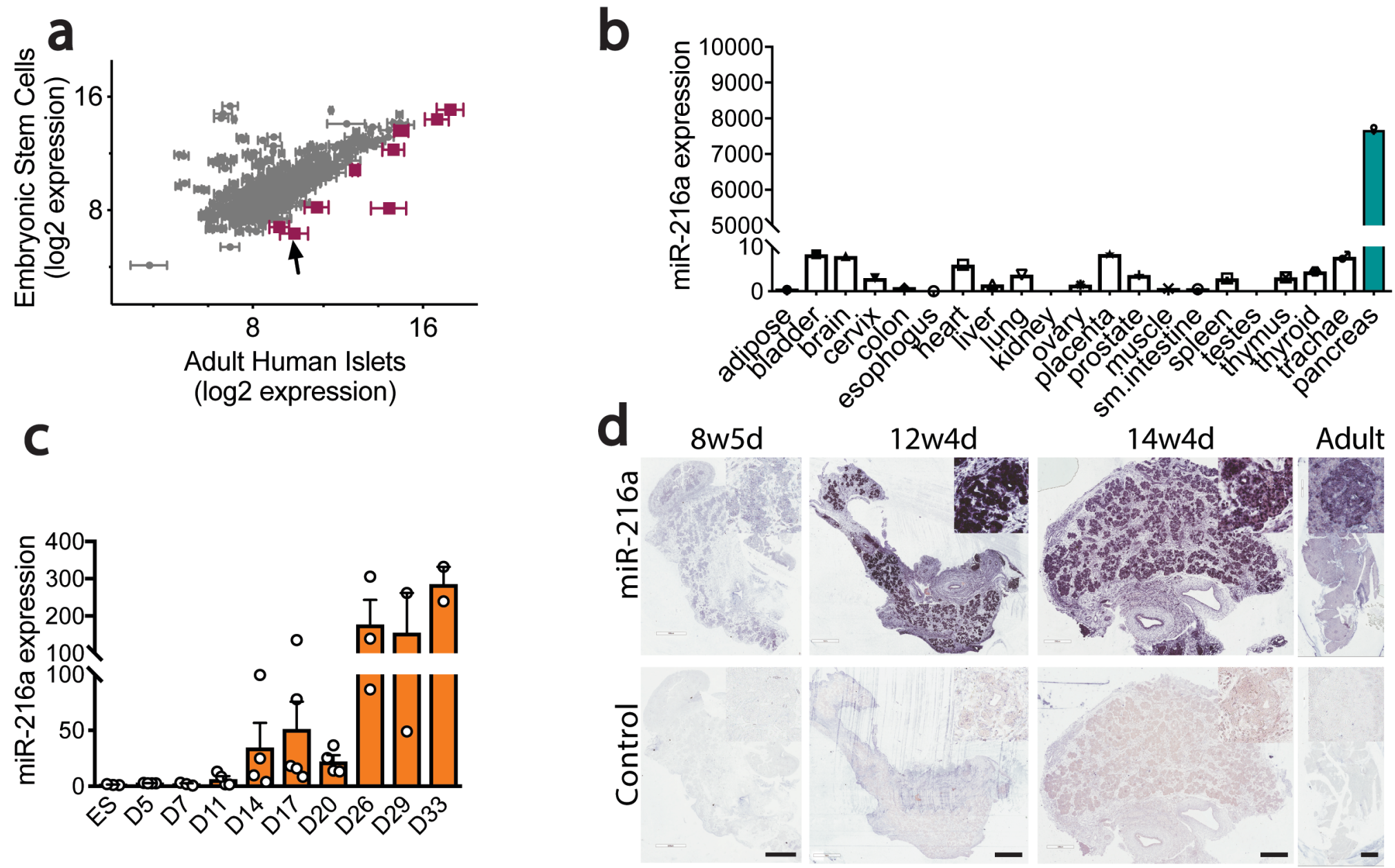

e

Homo Sapiens

Mus musculus

Rattus norvegicus

Danio rerio

Gallus gallus

Pan troglodytes

Pongo pygmaeus

Capitella teleta uaaucucagcuggcaacuguga uaaucucagcuggcaacuguga uaaucucagcuggcaacugug uaaucucagcuggcaacuguga uaaucucagcuggcaacuguga uaaucucagcuggcaacugug uaaucucagcuggcaacugug uaaucucagcuggcaacuguga

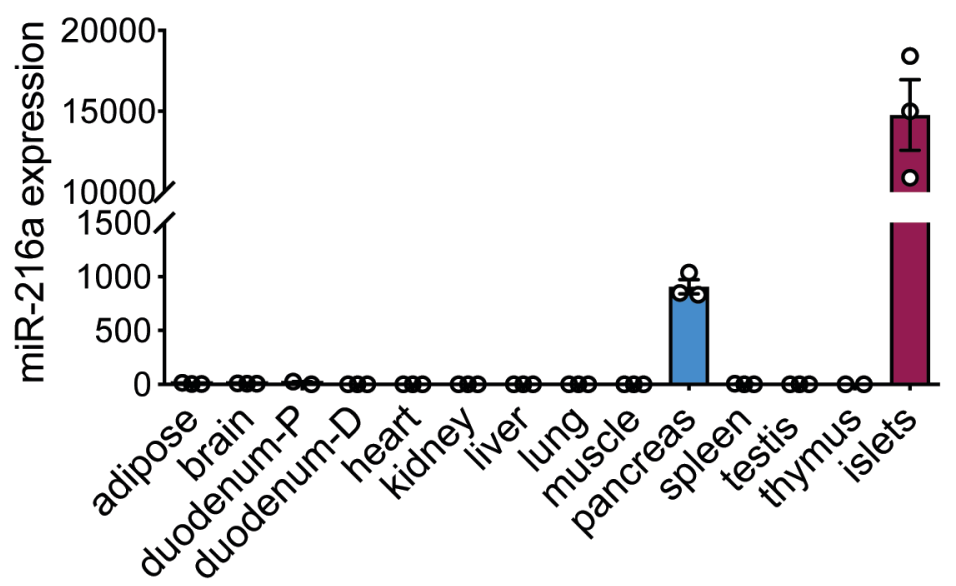

Figure 1. miR-216a is enriched in pancreatic islets and is highly conserved among various species. a miRNA profiling of adult human islets compared to human embryonic stem cells. miRNAs with greater than 3-fold increase in the islets are shown in red. Arrow points at miR-216a. $n=3$. Data represent mean log2 signals $\pm S E M$ (from human islets). b Equal amounts of RNA from various human tissues (each a pool of 3 tissue donors) was reverse-transcribed and miR-216a expression was determined by qRT-PCR. Threshold cycle $33(\mathrm{Ct}=33)$ was arbitrarily set as 1 . c Human embryonic stem (ES) cells were differentiated to pancreatic endocrine cells for the indicated days and miR-216a expression was measured by qRT-PCR and expressed relative to levels in undifferentiated ES cells. $\mathbf{d}$ Fetal and adult human pancreata were probed with DIG-labeled miR-216a and scrambled control miRNA probes at the indicated gestational weeks. Purple color indicates presence of miRNA expression. Scale bar=1 mm (12w4d, Adult), Scale bar = $500 \mu \mathrm{m}(8 \mathrm{w} 5 \mathrm{~d}, 14 \mathrm{w} 4 \mathrm{~d})$. Insets are enlarged 20x. e Comparison of mature miR-216a sequences in different species. $f$ Same as in (b) except that the tissues were harvested from 8-week old C57BL/6 male mice. $n=3$. Individual data points are shown in $c$ and $f$ and data represent mean \pm SEM. 
Figure 2
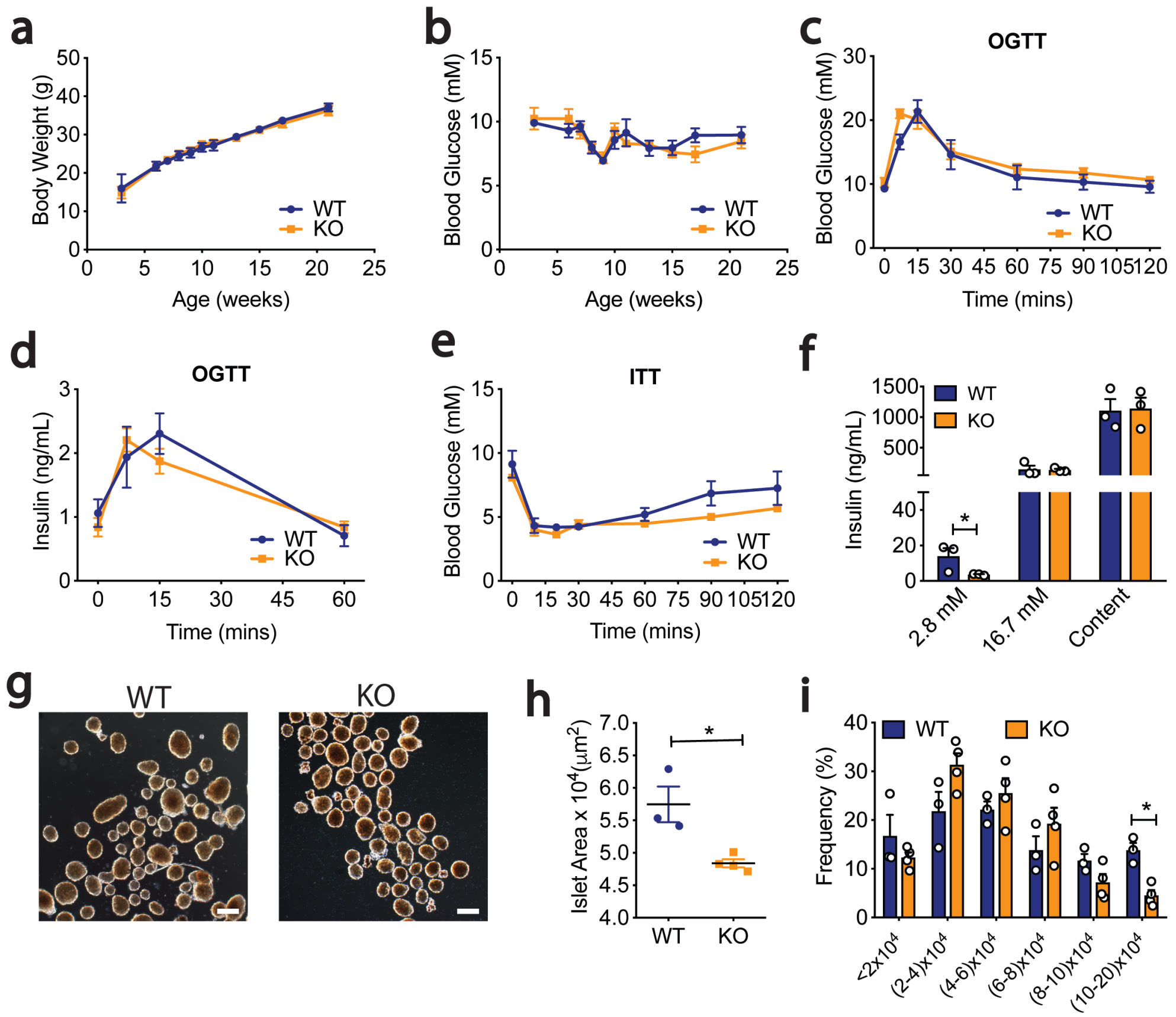

Figure 2. miR-216a knock-out (KO) mice have smaller islets than wild-type (WT) mice. WT and miR-216a KO male mice on regular chow diet were monitored for body weight (a) and blood glucose (b) for 21 weeks. $n=4-7$. Oral glucose tolerance test (OGTT) performed in 10-week old male mice, with measurement of blood glucose levels (c) and plasma insulin concentration (d). e Insulin tolerance test (ITT) in 12-week old male mice injected with $1 \mathrm{U} / \mathrm{kg}$ insulin at time $=0$ and blood glucose levels determined th the indicated time points. $\mathrm{f}$ Insulin content and secretion from islets isolated from male WT and KO mice exposed to $2.8 \mathrm{mM}$ and $16.7 \mathrm{mM}$ glucose. $\mathrm{n}=3$. $\mathrm{g}$ Representative images of isolated islets from 10-week old male WT and KO mice. Scale bar $=100 \mu \mathrm{m}$. $\mathrm{h}$ Average size of isolated islets and the distribution of islet size (i). $\mathrm{n}=3-4$. A two-tailed Student's t-test was performed to assess significance. ${ }^{*} p<0.05$ Individual data points are shown in $\mathbf{f}, \mathbf{h}$, and $\mathbf{i}$. Data represent mean \pm SEM. 


\section{Figure 3}
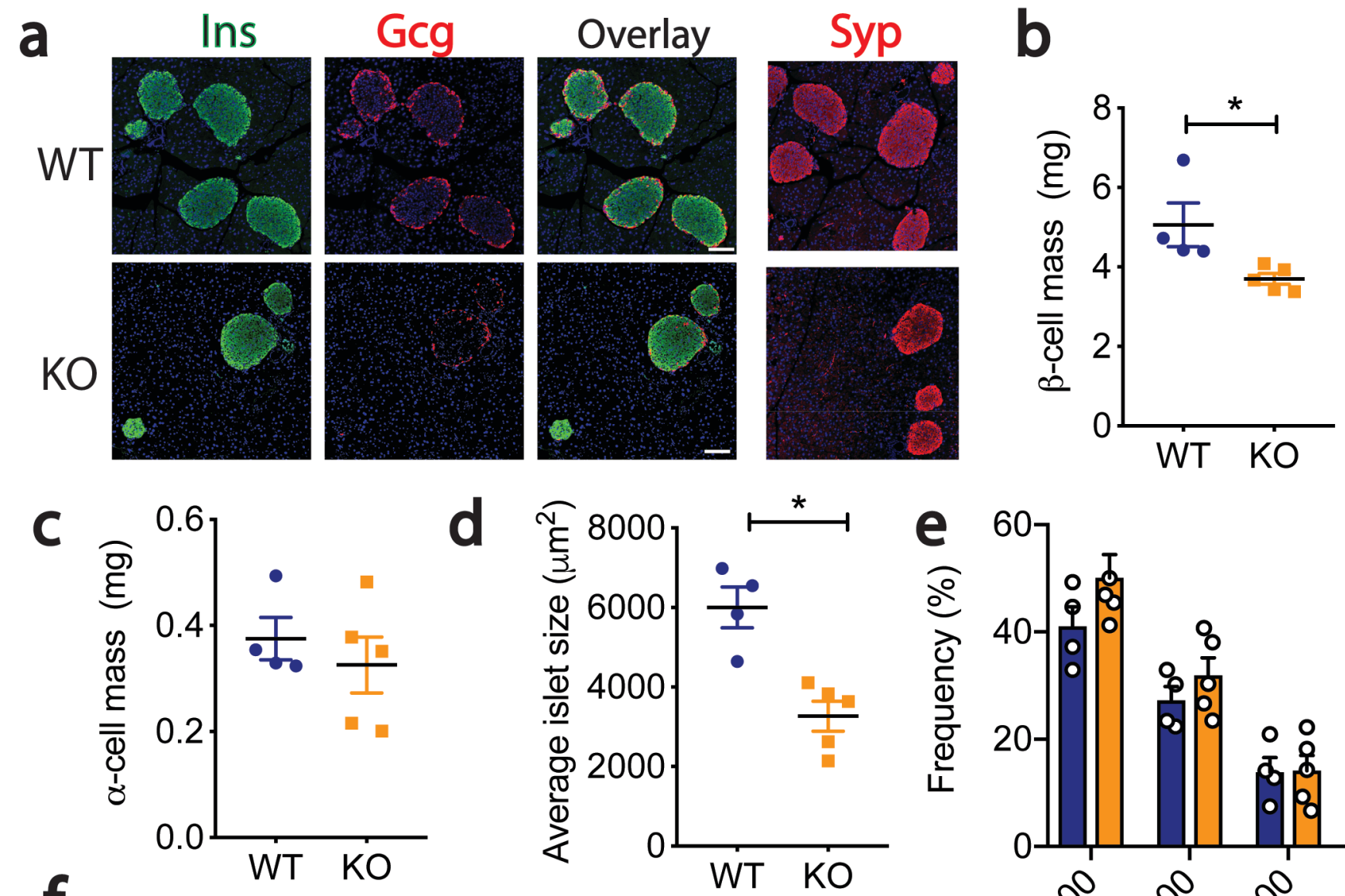

9
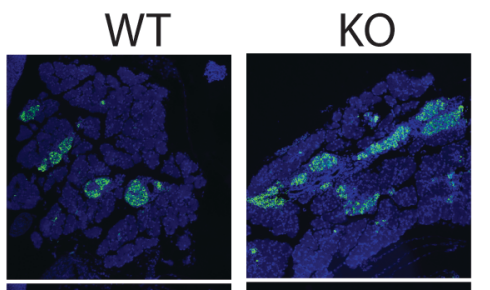

0

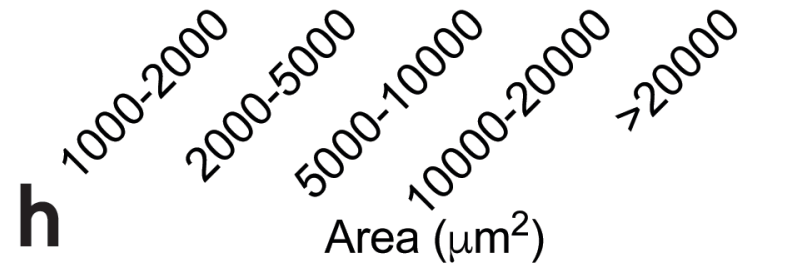

\section{宁}
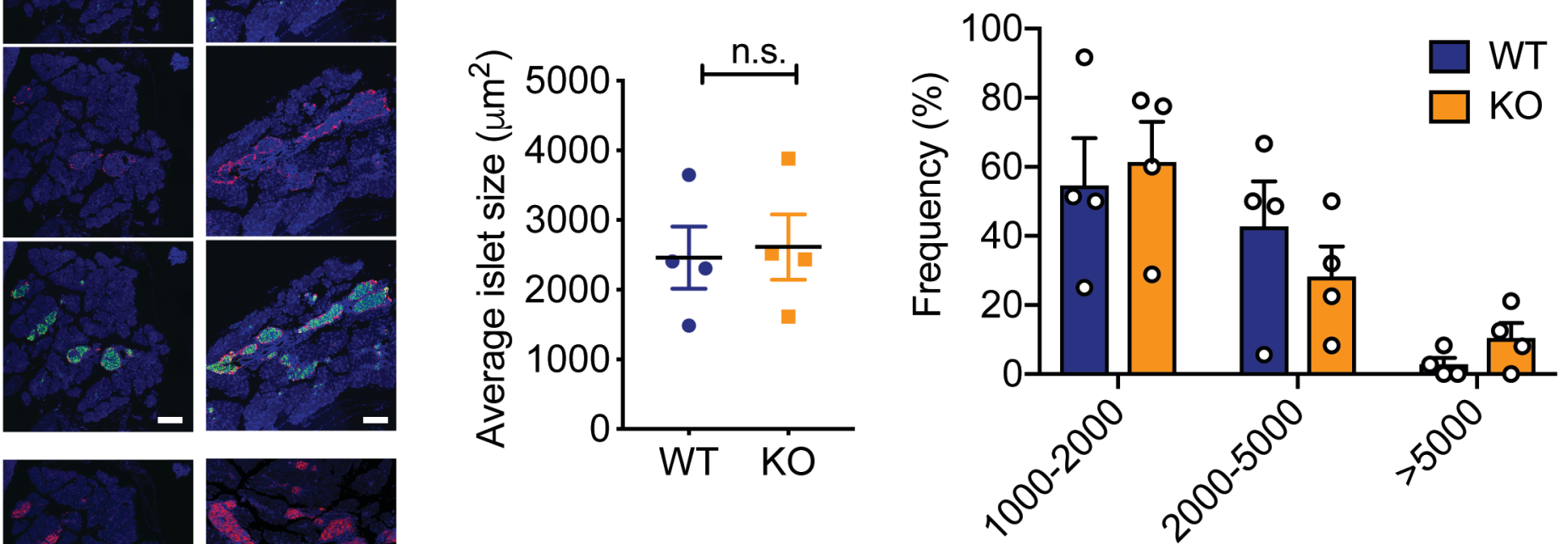

Area $\left(\mu \mathrm{m}^{2}\right)$

Figure 3. $\beta$-cell mass is reduced in miR-216a KO mice. a-e Pancreata from 21-week old male WT and KO mice were immunostained for insulin, glucagon and synaptophysin. a Representative images of insulin (Ins), glucagon (Gcg) and synaptophysin (Syp) immunostaining, along with an overlay of Ins and Gcg. Nuclei were identified with dapi (blue). Scale bars $=100 \mu \mathrm{m}$. b $\beta$-cell mass, c a-cell mass, $\mathbf{d}$ Average islet size, and e Islet size distribution. $\mathrm{n}=4$-5. $\mathrm{f}$ - $\mathrm{h}$ Pancreata from 1-day old male WT and KO mice were immunostained for insulin, glucagon and synaptophysin. $f$ Representative images of insulin (Ins), glucagon (Gcg) and synaptophysin (Syp) immunostaining, along with an overlay of Ins and Gcg. Nuclei were identified with dapi (blue). Scale bar $=100 \mu \mathrm{m}$. $\mathbf{g}$ Average islet size, and $\mathbf{h}$ Islet size distribution. A two-tailed Student's t-test was performed to assess significance. ${ }^{*} p<0.05$. Individual data points are shown in (b-e, g-h). Data represent mean \pm SEM. 

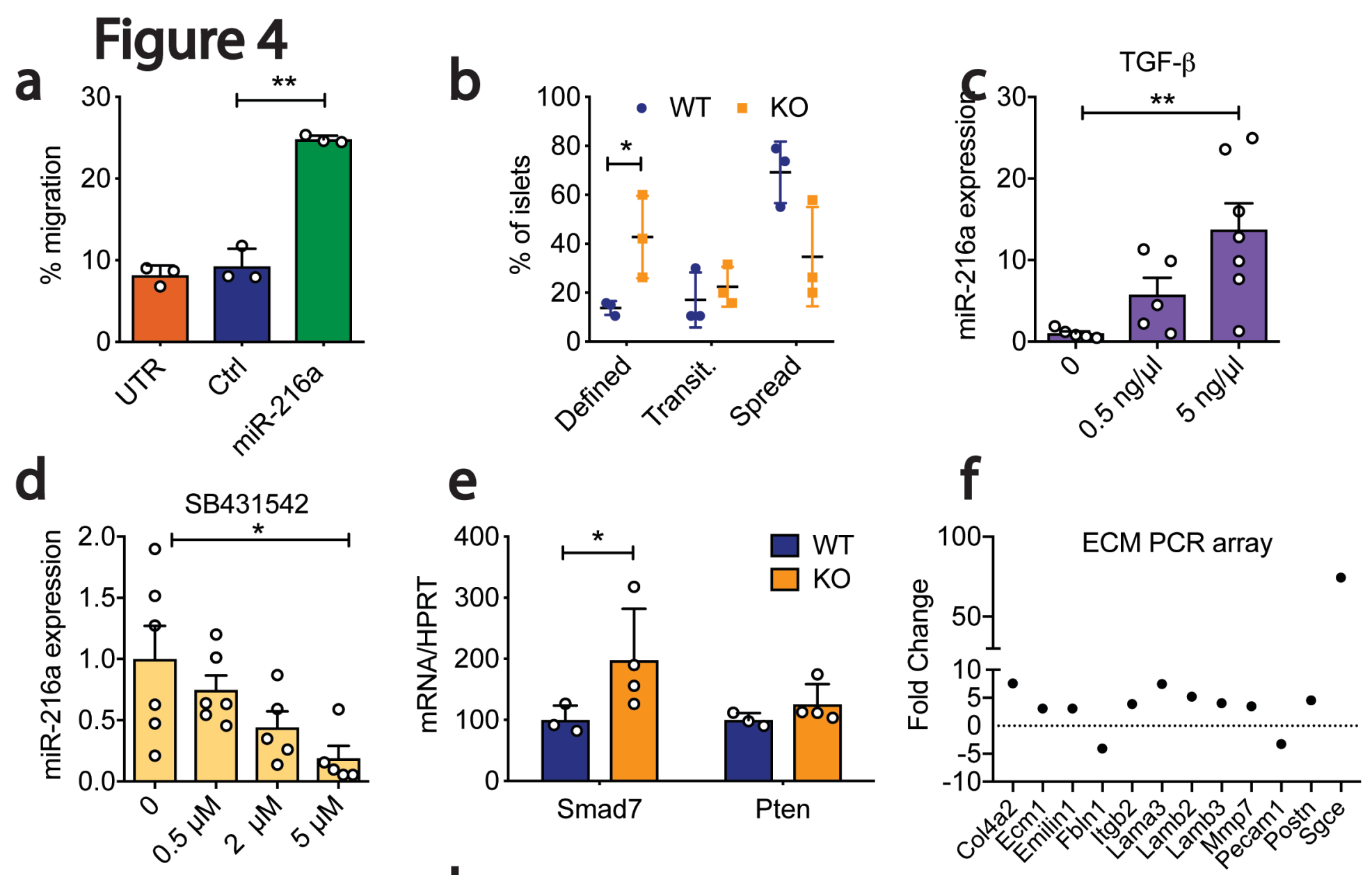

g
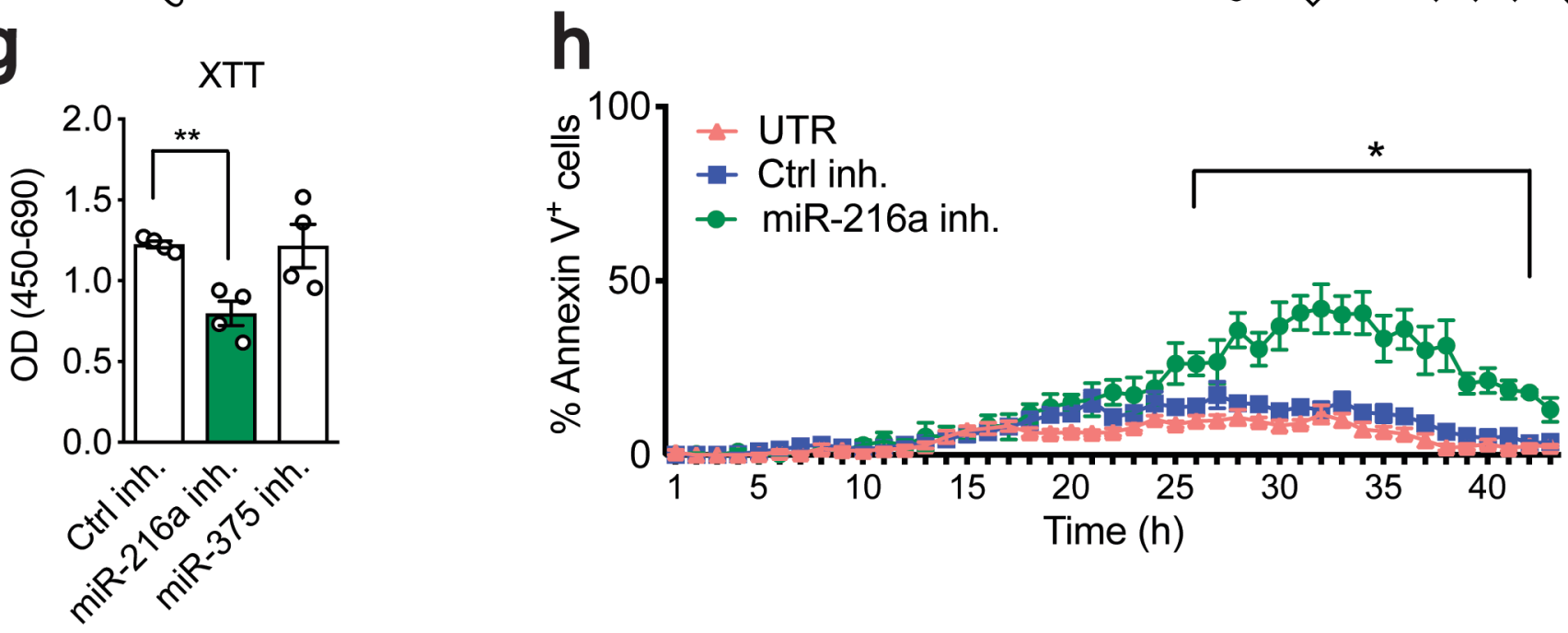

Figure 4. miR-216a regulates cell migration and apoptosis. a Percent of calcein stained PANC-1 cells migrating through a transwell following transfection with miR-216a or control (Ctrl) mimetics or untransfected (UTR). $\mathbf{n}=3 . \mathbf{b}$ Percent of islets isolated from 10-week old male WT or KO mice that appeared as either having defined, transitionary (transit.) or spread boundaries three days after plating on collagen wells. $n=3$. c-d Human EndoC- $\beta \mathrm{H} 1$ cells were treated with varying concentrations of c TGF- $\beta$ or d TGF- $\beta$ inhibitor SB431542 and miR-216a levels were quantified by qRT-PCR. $n=6$. e Islets-from 10-week old male WT and KO mice were isolated and expression of Smad7 and Pten was quantified with qRT-PCR. $n=3-4$. $\mathrm{f}$ MIN6 cells were transfected with miR-216a and control mimetics and expression of 84 ECM related genes was quantified by qRT-PCR. Genes displaying $>2$-fold difference are shown. Each value is the mean of 3 independent transfections. g-h INS1-E cells were transfected with the indicated miRNA inhibitors (inh.) or with a scrambled control miRNA inhibitor (Ctrl inh.) and cell viability was assessed by XTT (2,3-bis-(2-methoxy-4-nitro-5-sulfophenyl)-2H-tetrazolium-5-carboxanilide) assay (g) or live cell imaging using Hoechst and Alexa647 annexinV (h). TNF-a, IFN- $\gamma$ and IL- $1 \beta$ were added to media prior to imaging cells at $37^{\circ} \mathrm{C}$ and $5 \% \mathrm{CO} 2$ in an ImageXpress Micro. $\mathrm{n}=4$. A two-tailed Student's t-test $(\mathrm{a}-\mathrm{e}, \mathrm{g})$ or two-way ANOVA with Bonferroni's multiple comparison post-test $(h)$ were performed to assess significance. ${ }^{*} p<0.05,{ }^{* *} p<0.01$. Individual data points are shown in $(\mathbf{b}-\mathbf{e}, \mathbf{g}-\mathbf{h})$. Data represent mean \pm SEM. 
Figure 5

a

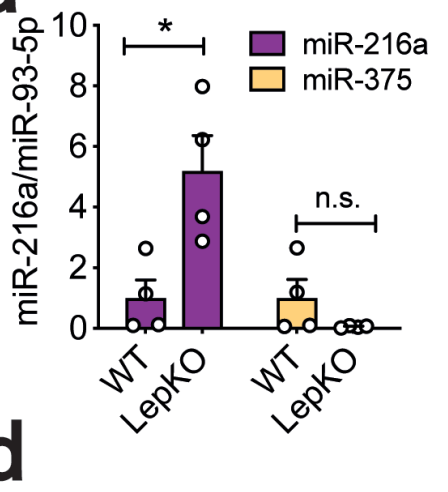

OGTT

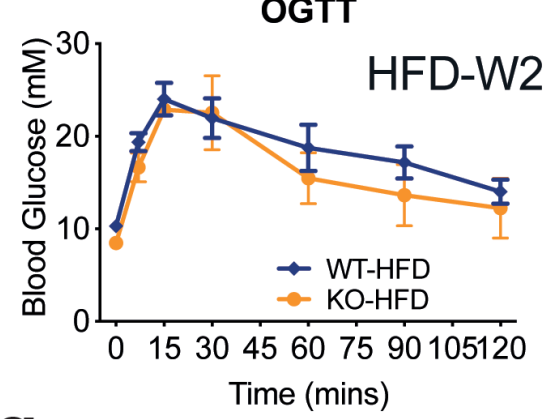

g
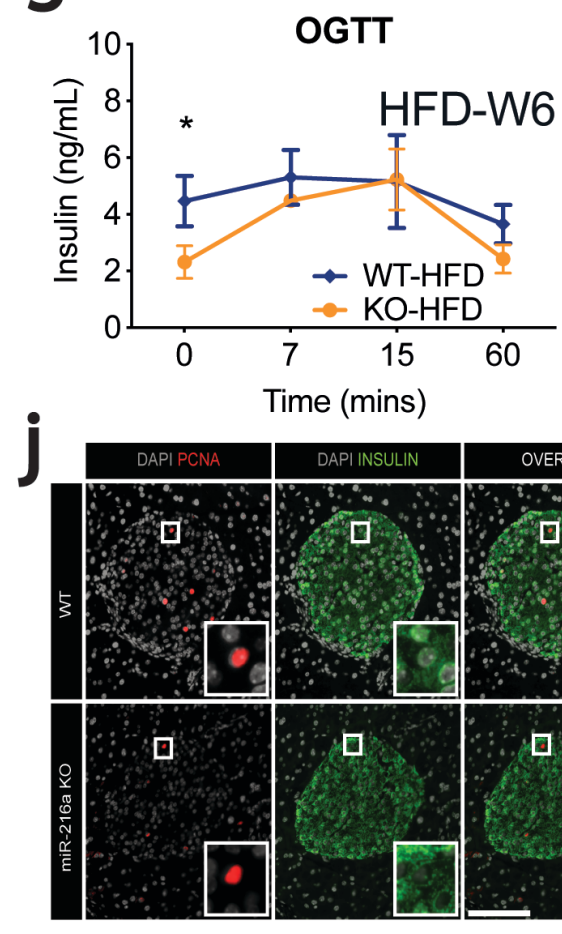

n

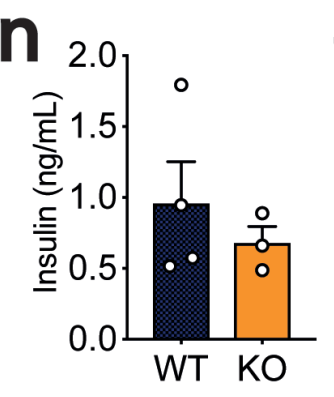

b

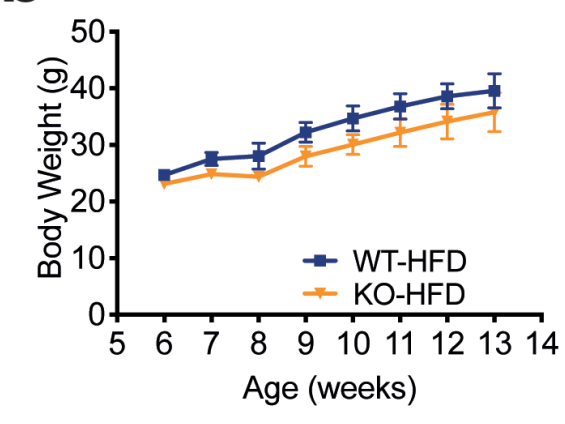

OGTT

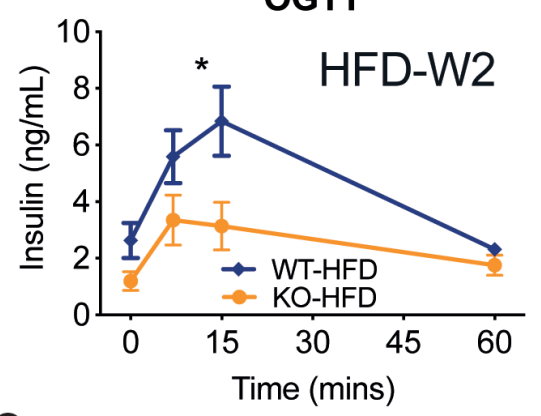

h
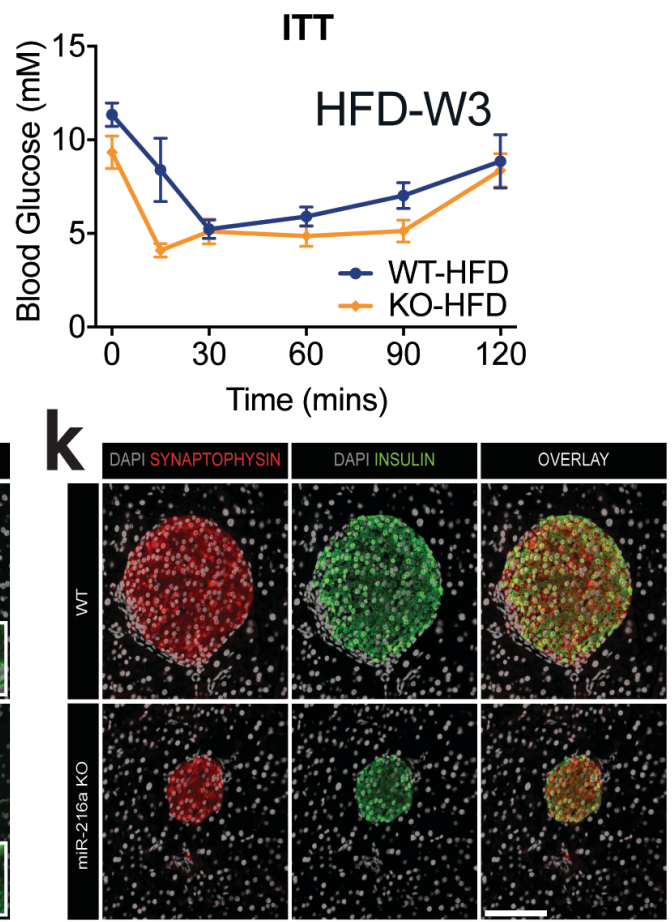

f
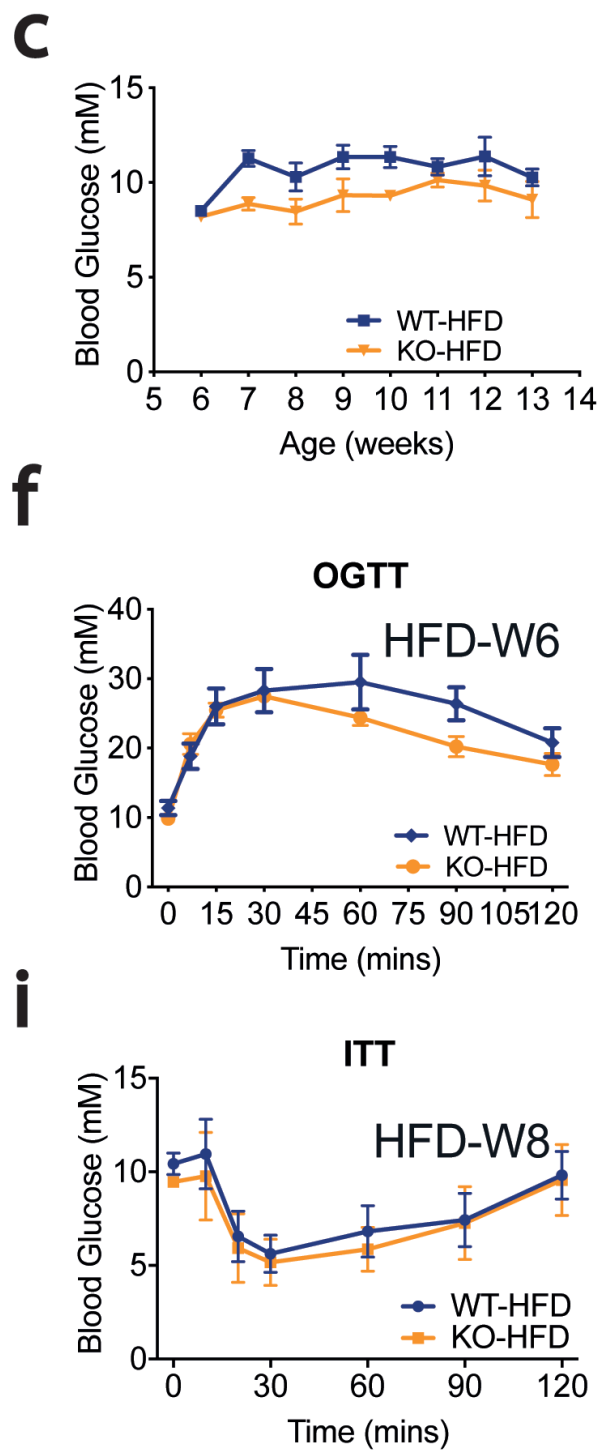

m

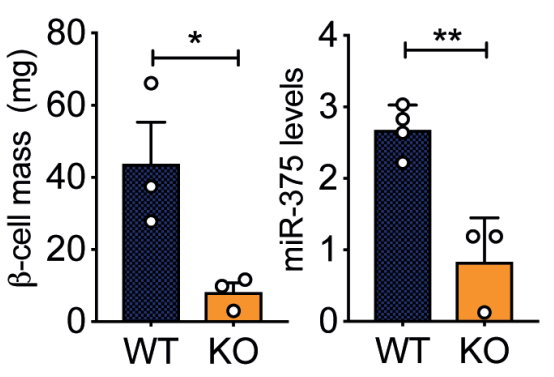

p

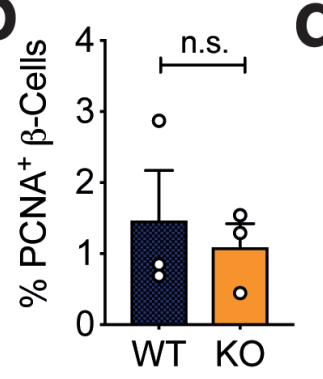

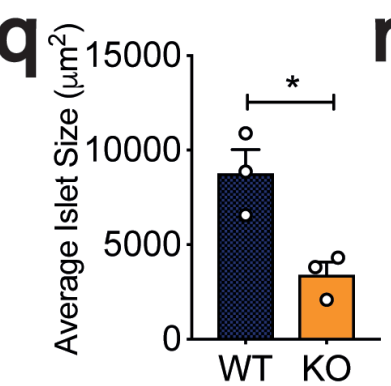

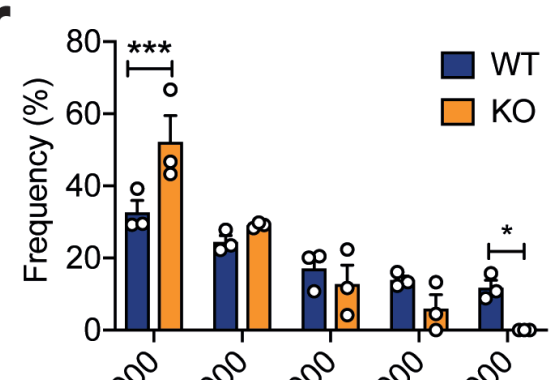


Figure 5. miR-216a KO mice have decreased $\beta$-cell mass and islet size on high-fat diet (HFD). a Islets were isolated from WT and Leptin knock-out male (LepKO) rats and expression of miRNAs was quantified by qRT-PCR and expressed relative to levels in WT cells. b-rWT and miR-216a KO male mice were fed with a 60\% HFD for 8-weeks and weekly body weight (b) and fasted blood glucose levels (c) were measured. $\mathbf{d}$-g Oral glucose tolerance tests (OGTT) were performed 2 weeks and 6 weeks post HFD, with measurement of blood glucose levels (d, f) and plasma insulin concentrations $(\mathbf{e}, \mathbf{g}) \cdot \mathbf{h}$, i Blood glucose levels during insulin tolerance tests (ITT) performed 3 weeks (h) and 8 weeks (i) post HFD. j-k Pancreata from WT and miR-216a KO mice were fixed and stained with the indicated antibodies 8 weeks post HFD. Representative images are shown. Scale bars $=100 \mu \mathrm{m}$. Insets are enlarged 4x. I, p, q Quantifications of insulin (l), PCNA (p) and synaptophysin (q-r) immunoreactivity. $n=3 . m$ qRT-PCR analysis for miR-375 from plasma of WT and miR-216a KO mice, 8-weeks post HFD, $n=4$. $n$ Plasma insulin o Plasma proinsulin levels from WT and miR-216a KO mice, 8-weeks post HFD, $n=3-4 . q$ Average islet size and $r$ islet size distribution based on synaptophysin immunostaining. A two-tailed Student`s t-test (a, I-r) or two-way ANOVA with Sidak`s multiple comparison post-test $(\mathbf{e}, \mathbf{g})$ were performed to assess significance. ${ }^{*} \mathrm{p}<0.05,{ }^{*} \mathrm{p}<0.01,{ }^{* * *} \mathrm{p}<0.001$. Individual data points are shown in $(\mathbf{a}, \mathrm{I}-\mathrm{r})$. Data represent mean \pm SEM. 


\section{Figure 6}
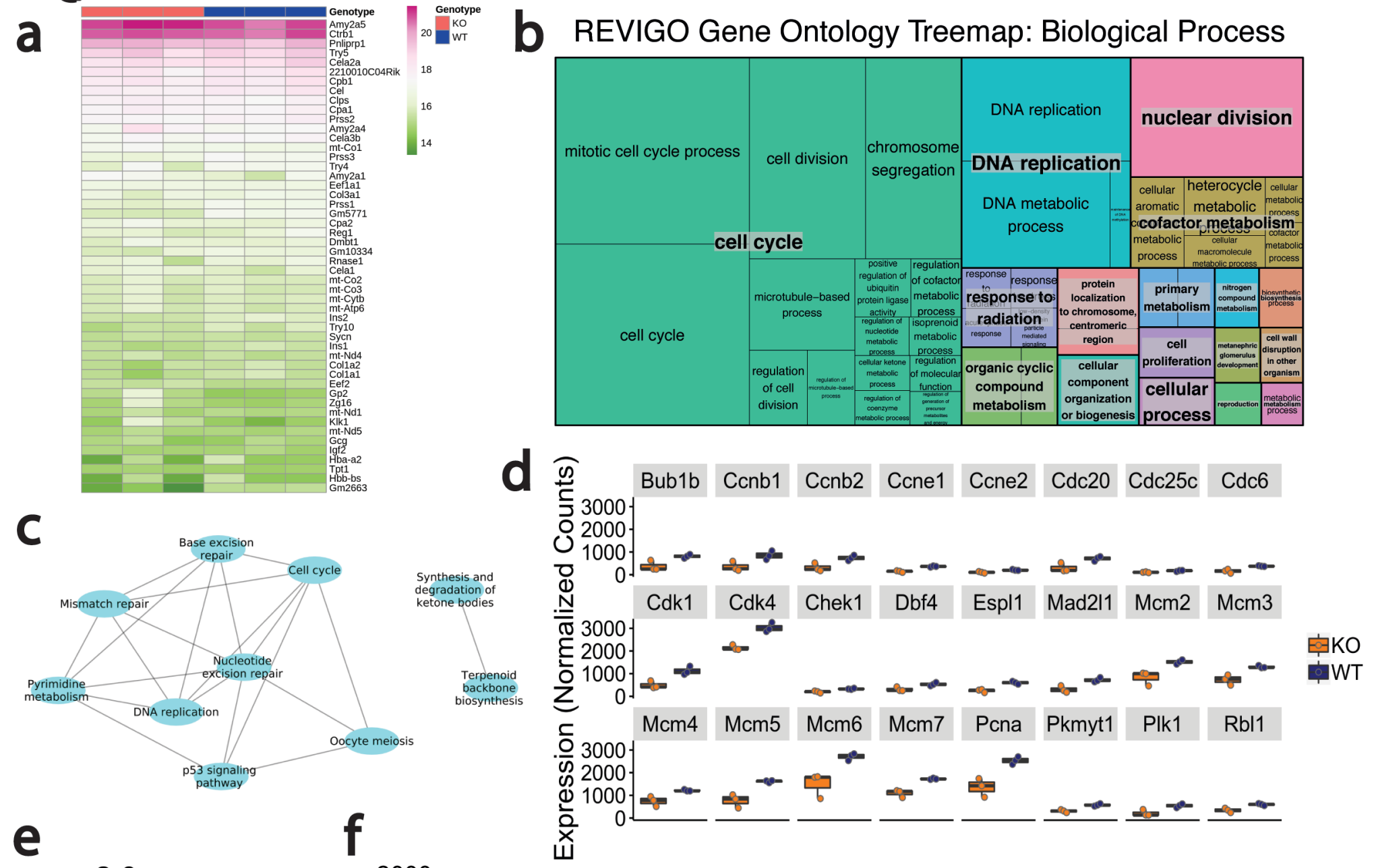

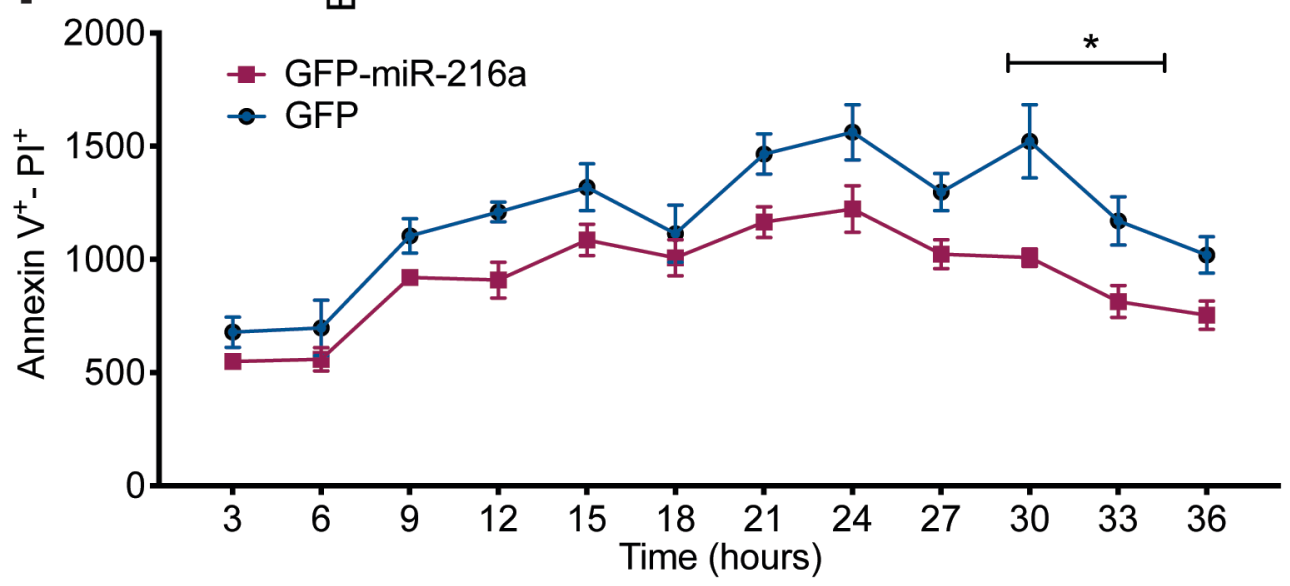

Figure 6. RNA-seq analysis of pancreata from miR-216a-KO mice. a RNA from the pancreata of 1-day old male WT and miR-216a KO mice was isolated and subjected to RNA sequencing and top 50 most abundant genes are shown by heat map. $\mathbf{b}$ A treemap plot, combining statistically significant GO terms in the biological processes category into similar terms. The size of the square increases with a decreasing $p$-value, and the colour of the square indicates the grouping of like terms (labelled in larger text with a grey background). Statistically significant terms were identified using hypergeometric tests with a false discovery rate of 0.1. c All statistically significant KEGG terms are shown in a network map, with nodes representing KEGG terms and edges connecting nodes representing differentially expressed genes in common between KEGG terms. Statistically significant terms were identified using hypergeometric tests with a false discovery rate of 0.1. $\mathbf{d}$ Normalized gene expression data for key genes of interest. All genes shown are differentially expressed, with adjusted $p$-values $<0.05$ (adjusted by the Benjamini Hochberg correction). e-f PANC-1 cells were transfected with the indicated miRNAs and 48-hours later TGF- $\beta$ was added to cell culture media and cell number was counted (e). Individual data points are shown. $\mathrm{n}=3$. $\mathrm{f}$ Cell death was assessed with live cell imaging using Hoechst and Alexa647 annexinV. Cells were imaged at $37^{\circ} \mathrm{C}$ and $5 \% \mathrm{CO} 2$ in an ImageXpress Micro. $n=$ 5. A two-tailed Student's t-test (e) or two-way ANOVA with Bonferroni’s multiple comparison post-test (f) were performed to assess significance. ${ }^{*} p<0.05$. Data represent mean $\pm S E M, n=3$. 
a

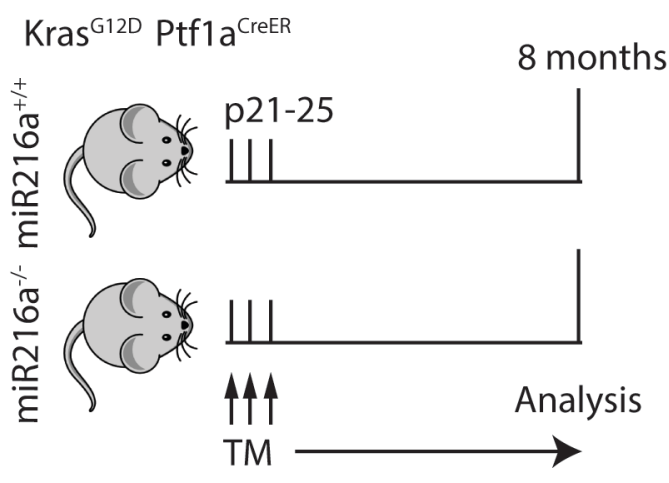

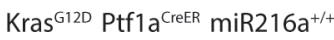

(WT)

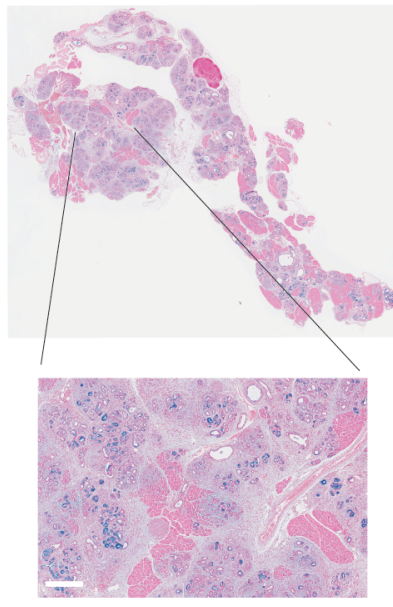

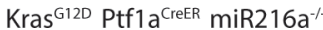

(KO)

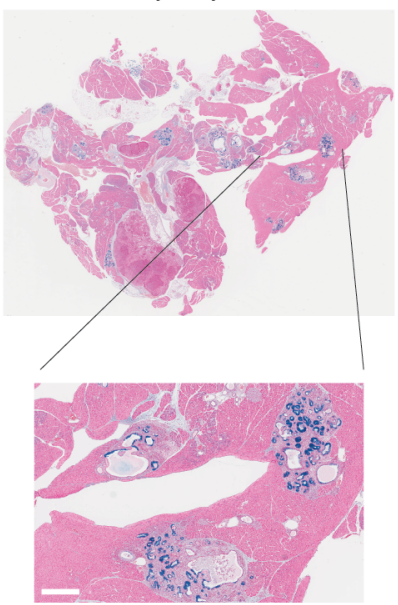

$\mathrm{Kras}^{\mathrm{G12D}}$ Ptf1 $\mathrm{a}^{\mathrm{CreER}}$ miR216a ${ }^{+/+}$

(WT)

b

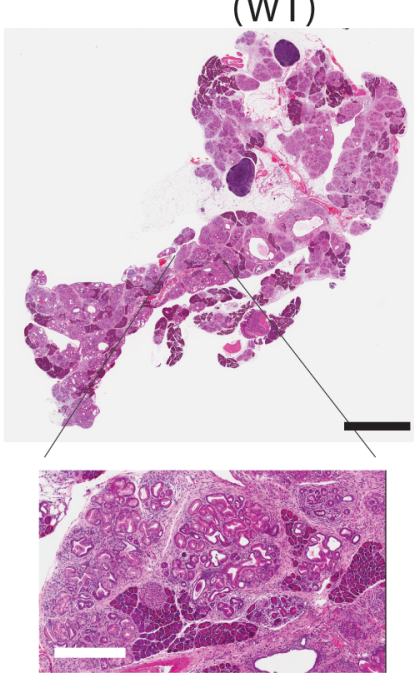

d
(KO)

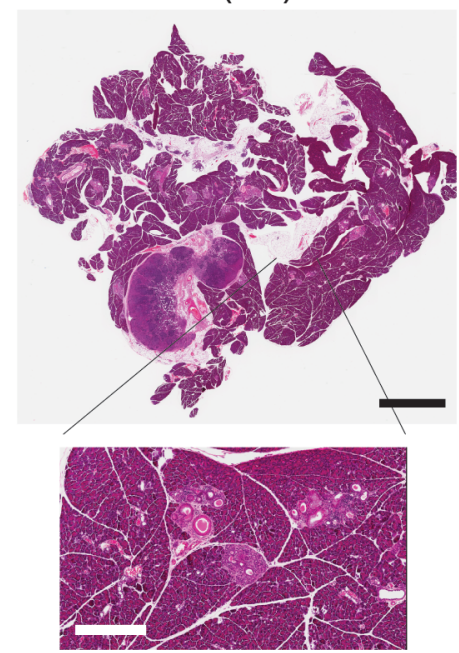

*

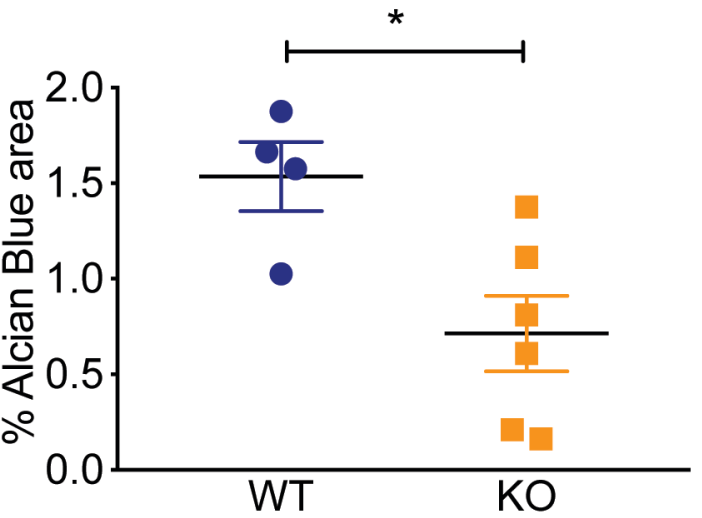

Figure 7. miR-216a-KO mice have lower incidence of pancreatic intraepithelial (PanIN) lesions. a Schematic showing the design of the study. Expression of KrasG12D was induced in exocrine cells by 3 tamoxifen injections on alternating days when the mice were 21-25 days old. Pancreata were harvested 8 months later. b Pancreatic H\&E staining. Scale bars (black) $=3 \mathrm{~mm}$, inset scale bars (white) $=400 \mu \mathrm{m}$. c Pancreatic alcian blue staining. Insets are $5 \mathrm{x}$ enlarged, inset scale bars $=400 \mu \mathrm{m}$. d Alcian blue positive area. Individual data points are shown. $\mathrm{n}=4-6$. A two-tailed Student's t-test was performed to assess significance. Data represent mean $\pm S E M . * 0<0.05$. 


\section{Supplementary 1}
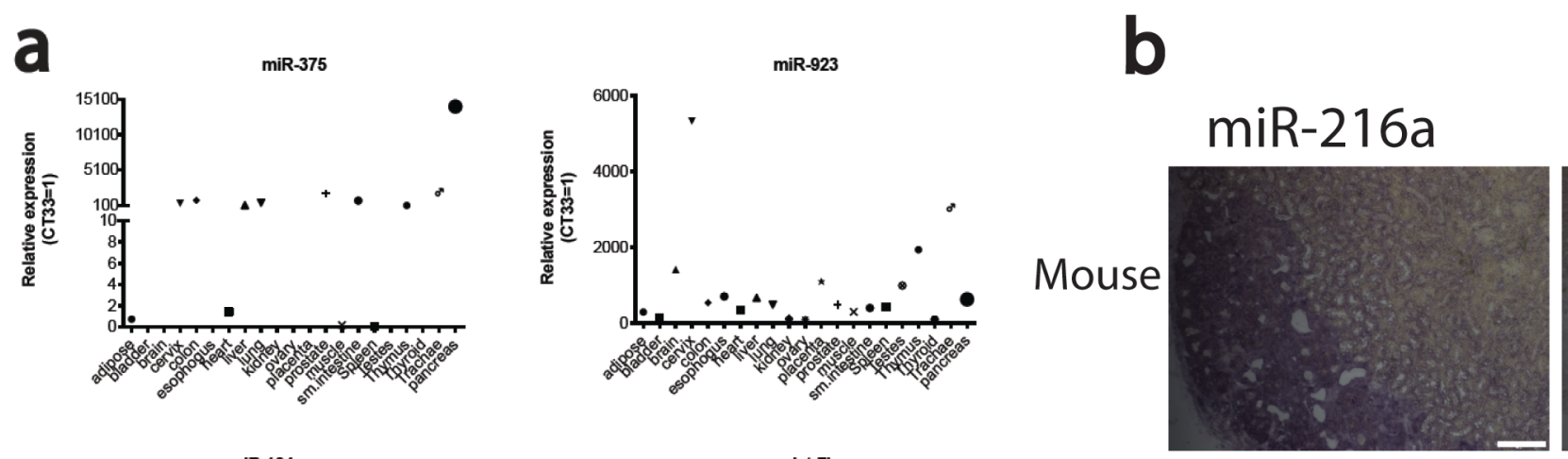

\section{Control}
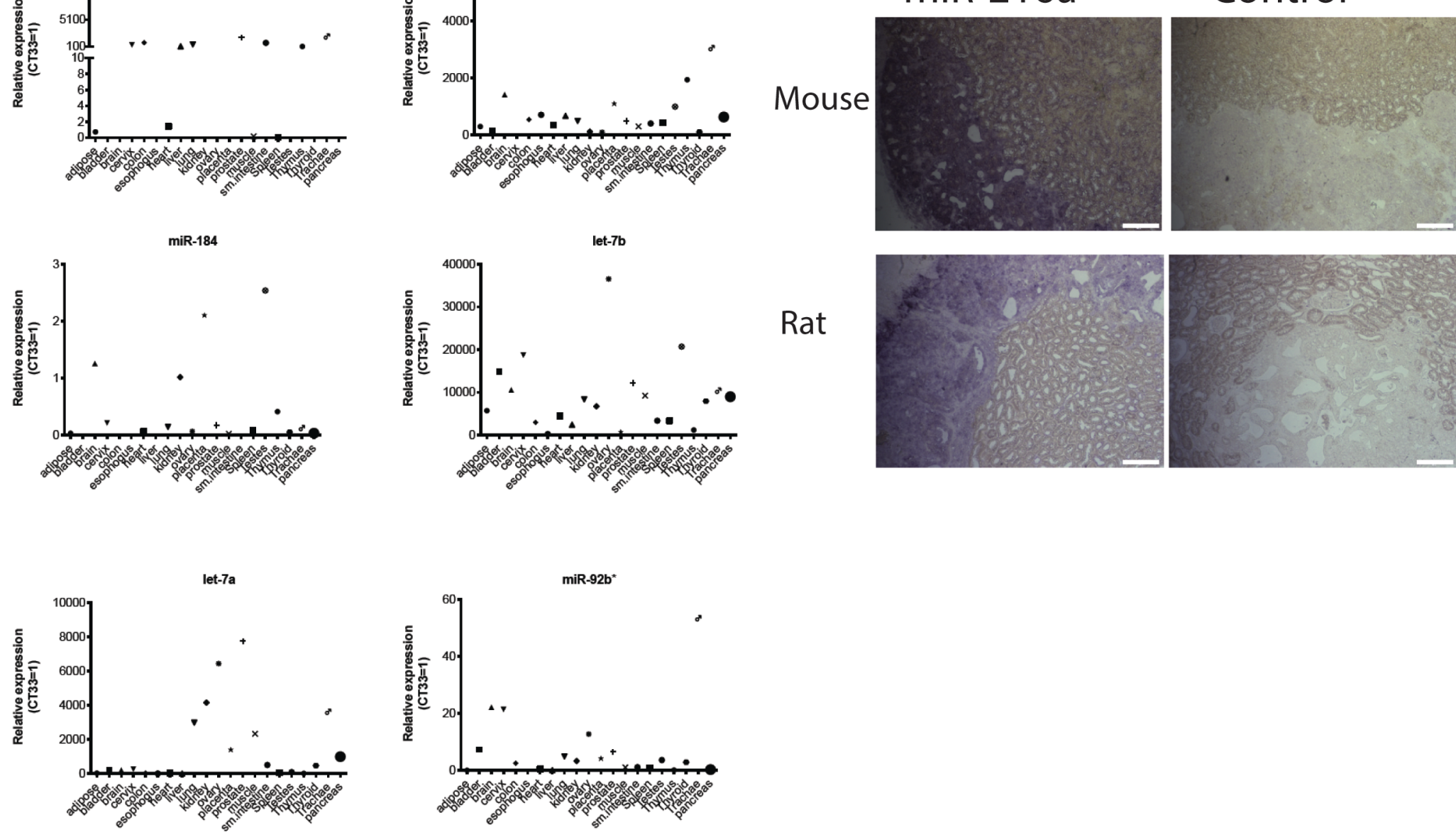

Suppl. Figure 1. a Expression of the indicated miRNAs in various human tissues. Equal amounts of RNA from human tissues (each a pool of 3 tissue donors) was reverse-transcribed and expression of indicated miRNAs was determined by qRT-PCR. Threshold cycle $33(\mathrm{Ct}=33)$ was arbitrarily set as 1 . b miR-216a is expressed in pancreatic tissue differentiated from hESCs. Representative in situ hydridization images of differentiated hESC-derived grafts at 22 weeks post implant in a mouse and a rat. Grafts harvested from mice and rats were probed with DIG-labeled miR-216a and scrambled miRNA control probes. Scale bars $=100 \mu \mathrm{m}$. 
a
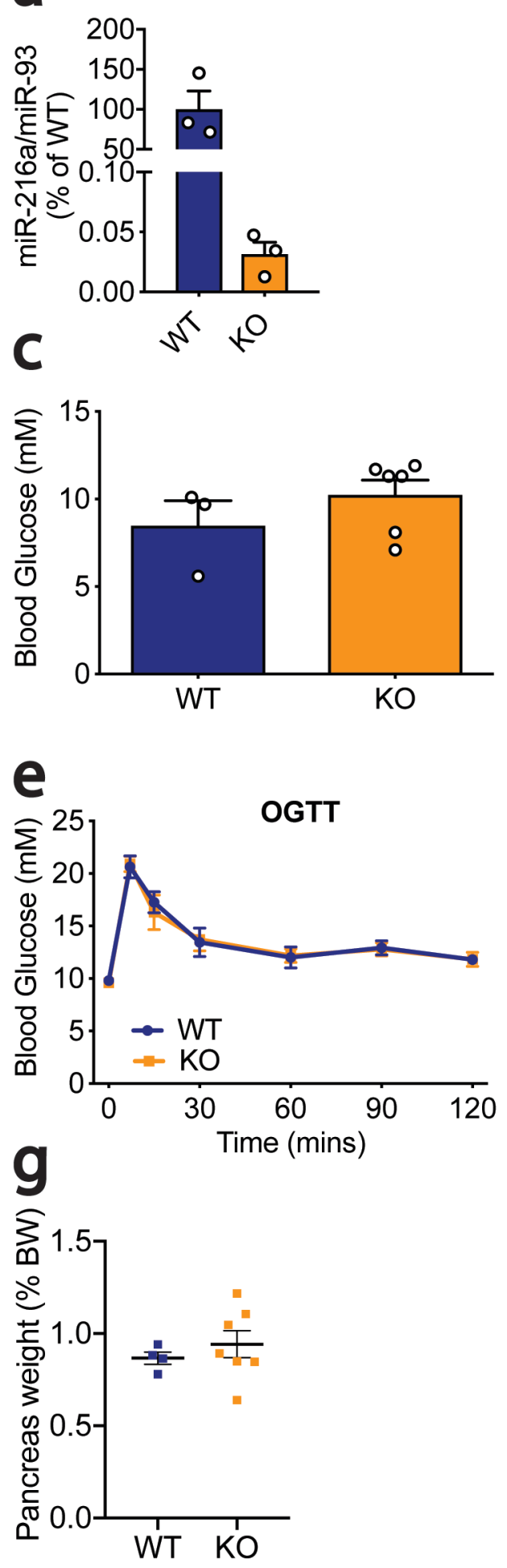

b
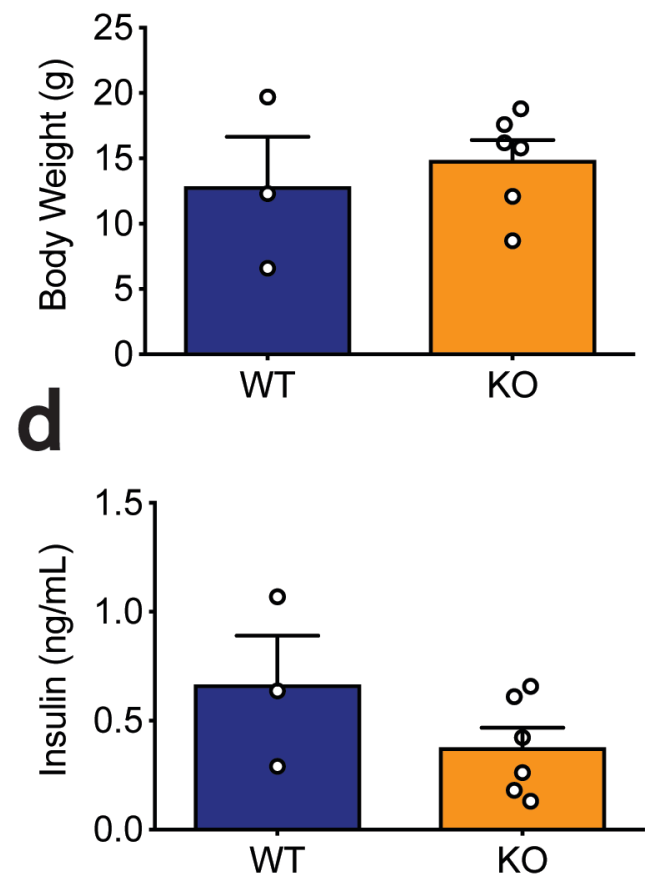

$f$
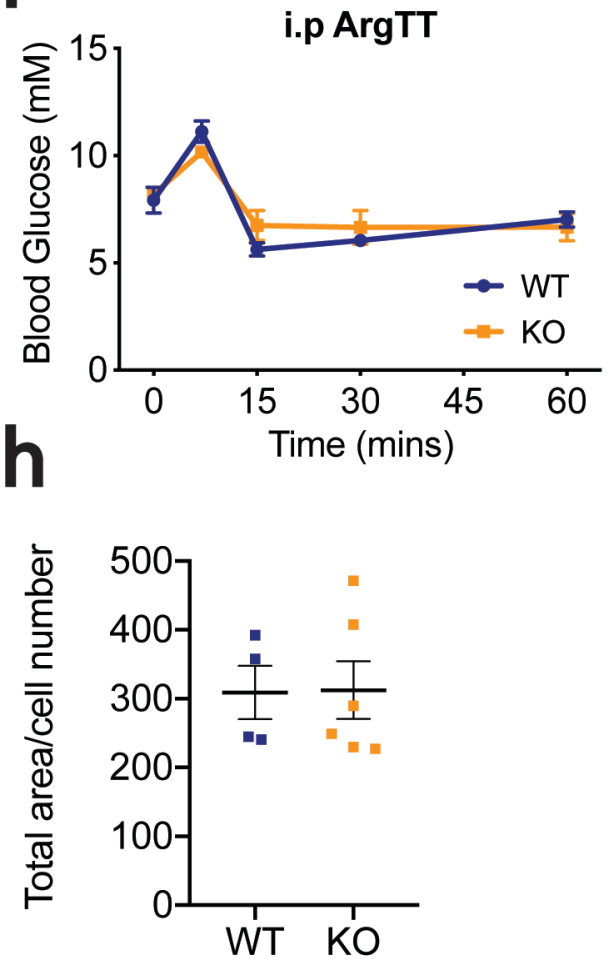

Suppl. Figure 2. miR-216a KO mice do not display alterations in glucose homeostasis. a Islets from 10-week old male WT and miR-216a KO mice were isolated and miRNA expression was quantified with qRT-PCR. $n=3 . \mathbf{b}-\mathbf{d}$ Body weight (b), fasting blood glucose (c), and insulin measurements (d) from 3-4 week old male mice. $n=3-6$. n.s. $=$ non-significant. $\mathrm{A}$ two-tailed Student's t-test was performed to assess significance. $\mathrm{e}$ Oral glucose tolerance (OGTT) test performed on 15-week old mice. $\mathrm{f}$ Intraperitoneal arginine tolerance test (i.p. ArgTT) performed on 18-week old mice. $n=4-6 . g$ Pancreata from 21-week old WT and miR-216a KO mice were weighed and normalized to body weight. $\mathbf{h}$ Pancreatic cell size was assessed by analyzing dapi staining from the pancreata of 21-week old male mice. Individual data points are shown in (a-d, $\mathbf{g}-\mathbf{h})$. Data represent mean $\pm \mathrm{SEM}$. 


\section{Supplementary 3}

a Islet Circularity

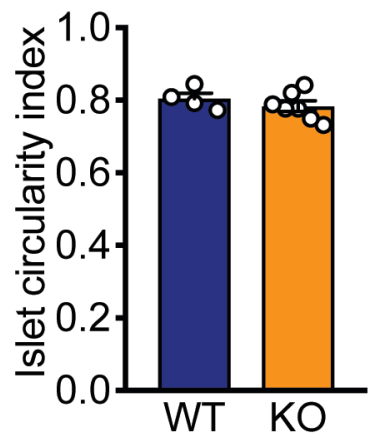

b

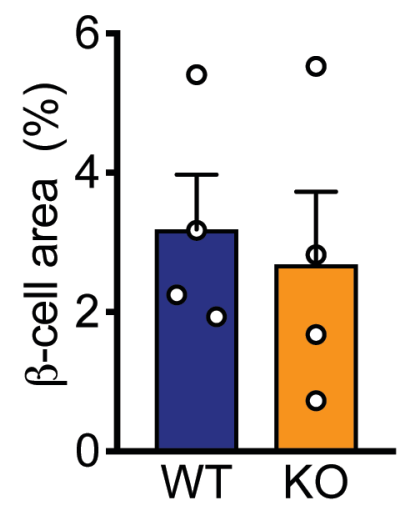

C Islet Circularity

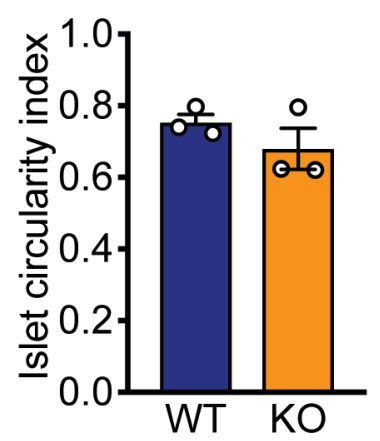

Peripheral $\alpha$-Cells
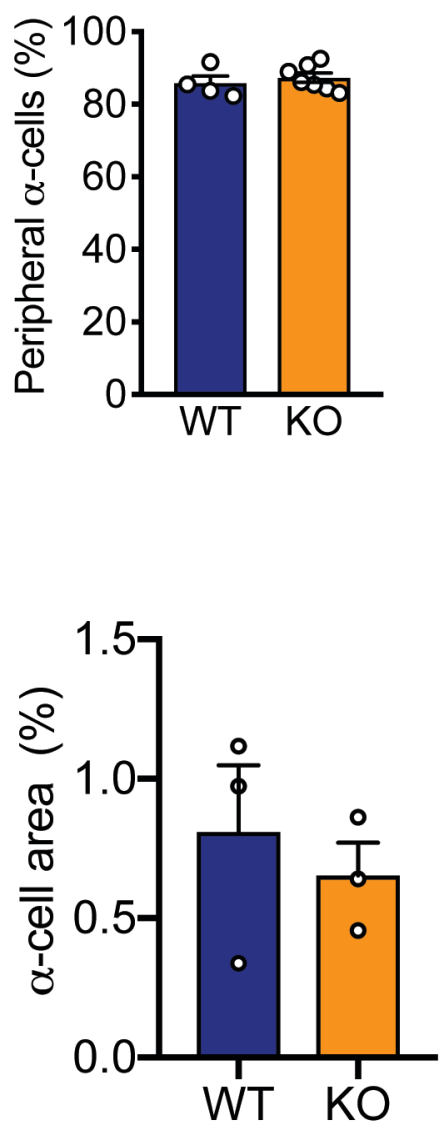

Peripheral $\alpha$-Cells

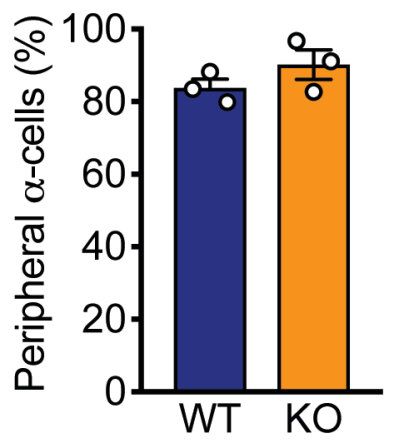

Suppl. Figure 3. Islet circularity and peripheral a-cell numbers are unchanged in miR-216a KO mice. Pancreata from adult male mice $(a ; n=4-7)$ and 1 -day old male neonatal mice $(b-c ; n=3-4)$ were immunostained for synaptophysin, insulin and glucagon, and islet circularity, peripheral $\alpha$-cell percentage, $\beta$-cell area, and $\alpha$-cell area were calculated. Individual data points are shown. Data represent mean \pm SEM. 


\section{Supplementary 4}

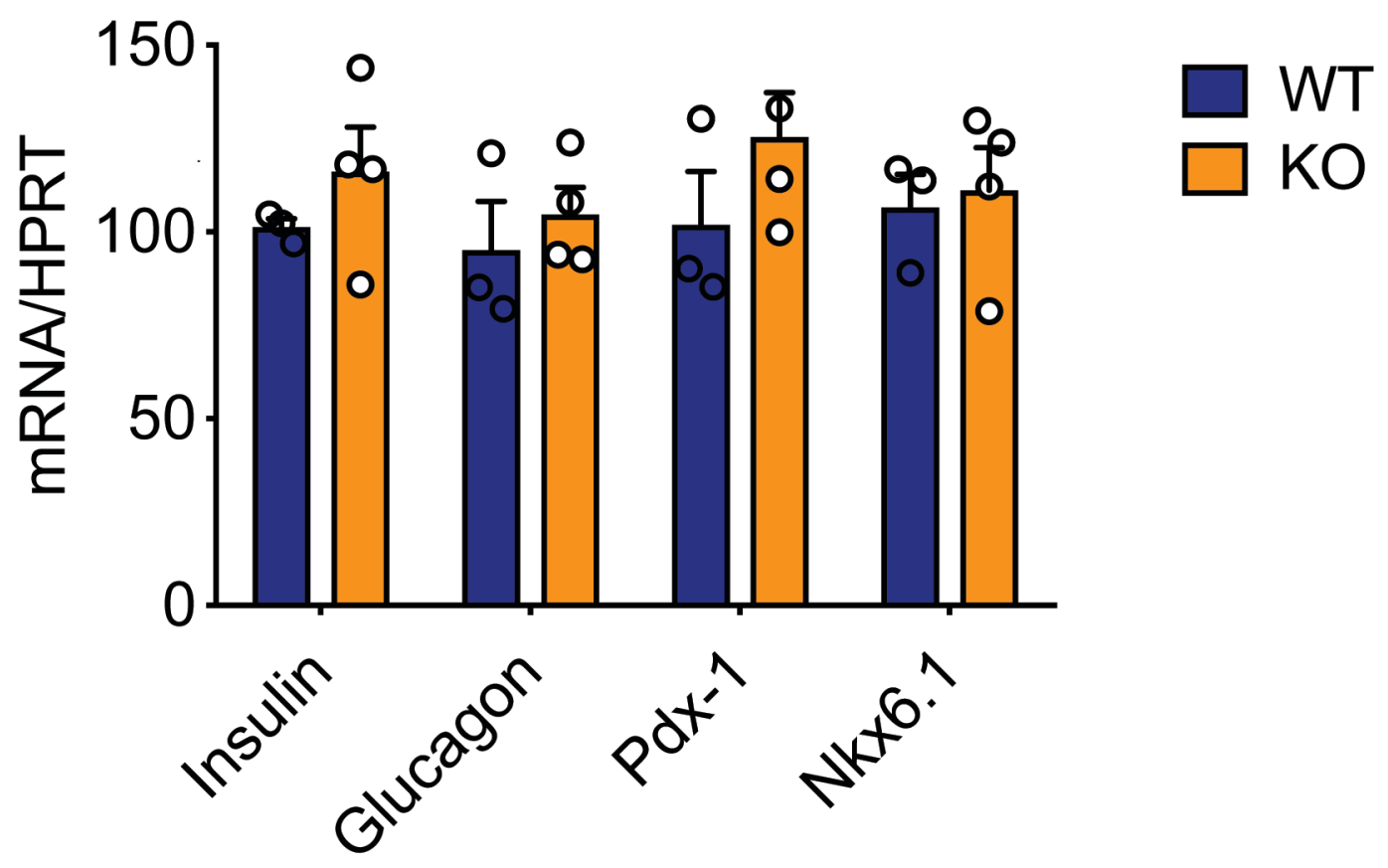

Suppl. Figure 4. Gene expression analysis using islets isolated from 10-week old male WT and miR-216a KO mice. RNA was isolated, reverse-transcribed and expression of the indicated genes was determined by qRT-PCR. WT levels arbitrarily set as 100. $n=3-4$. Individual data points are shown. Data represent mean \pm SEM. 


\section{Supplementary 5}

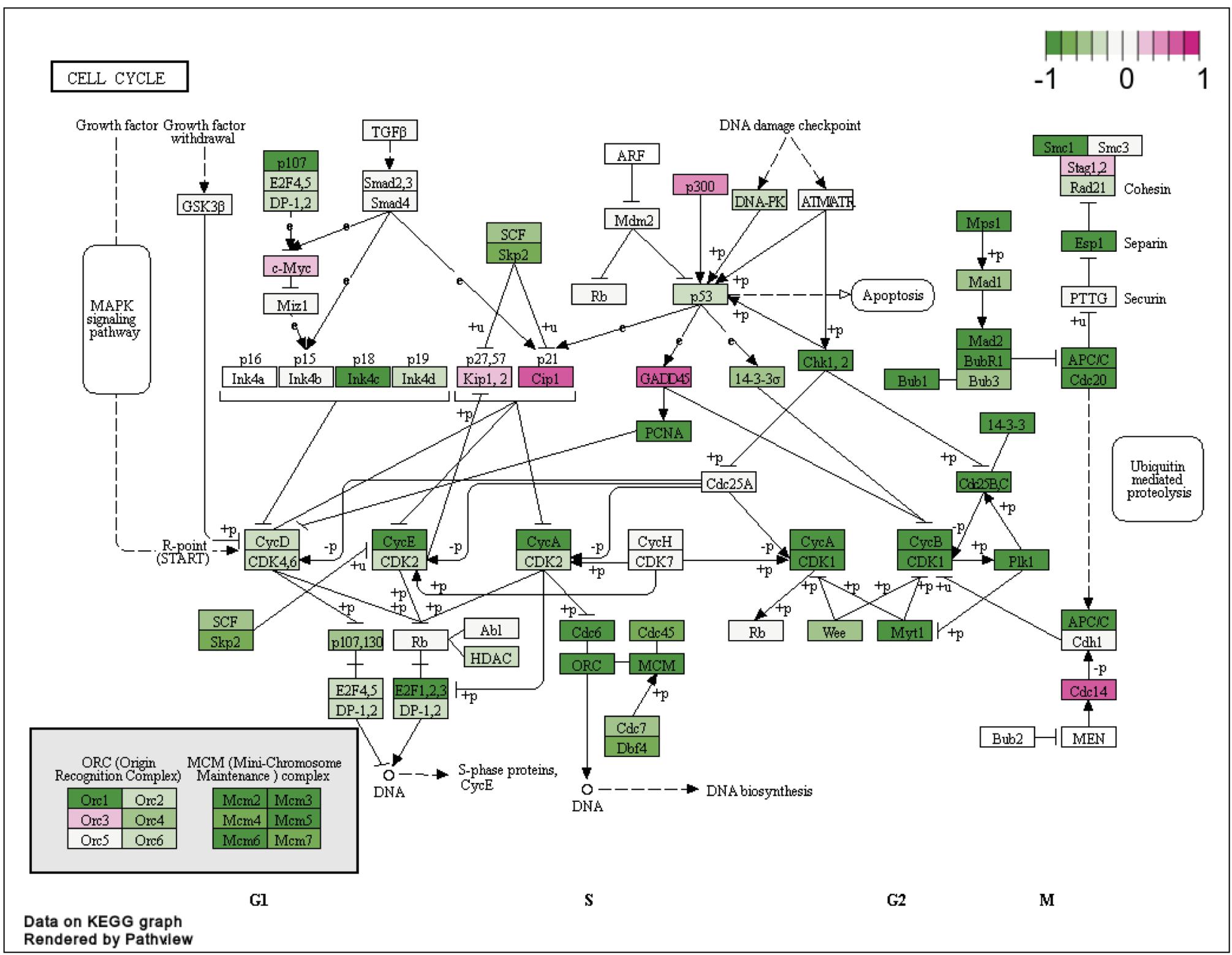

Suppl. Figure 5. A cell cycle pathway map, with genes significantly upregulated in miR-216a KO mice compared to WT mice shown in purple, and genes significantly downregulated in the KO mice compared to WT mice shown in green. Cell cycle is a significantly enriched GO "Biological Process" and KEGG term, with statistical significance defined as a $q$ value $<0.1$ (therefore allowing a 10\% FDR). 